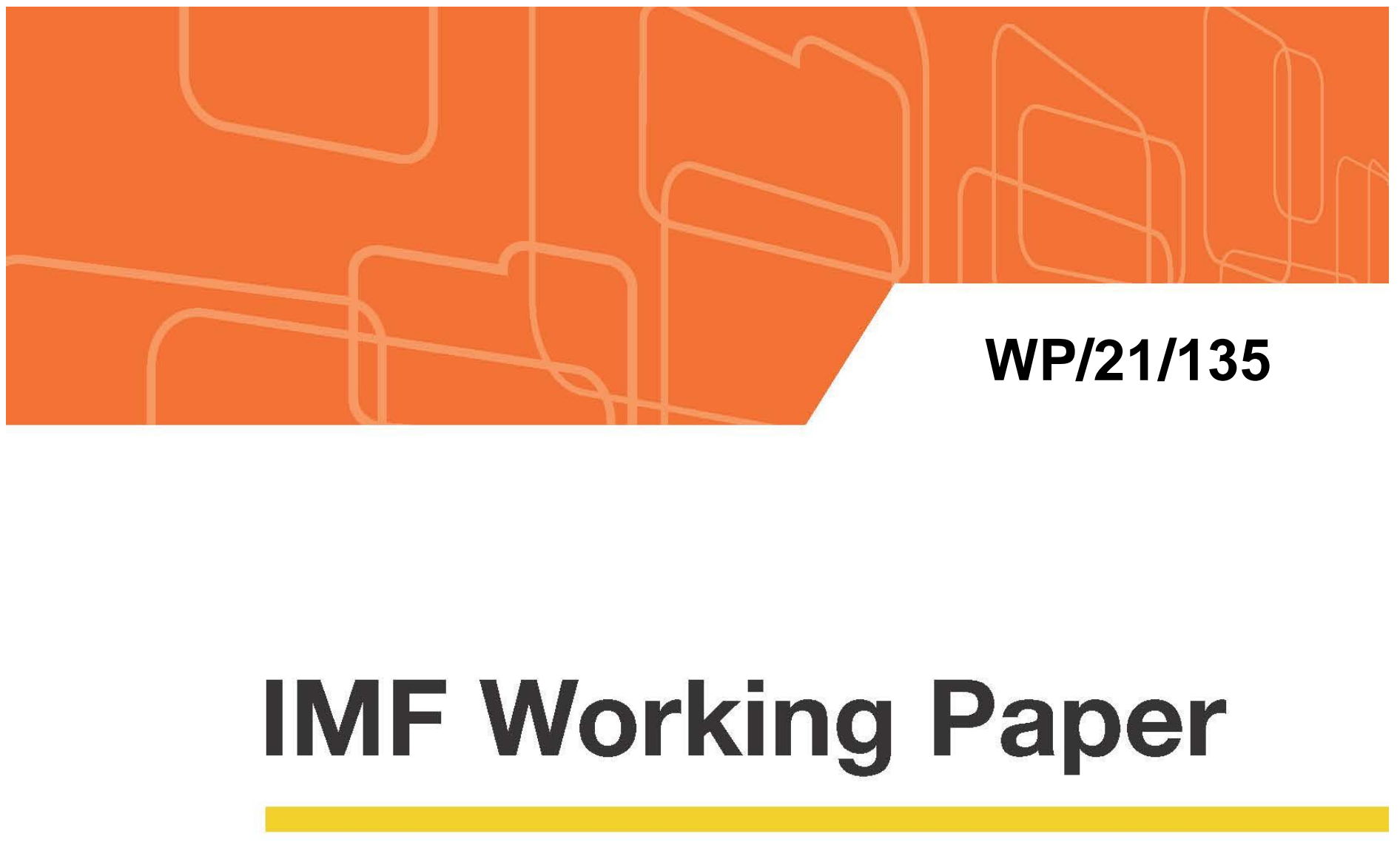

\title{
The Macroeconomic Impact of Social Unrest
}

by Metodij Hadzi-Vaskov, Samuel Pienknagura, and Luca Antonio Ricci

IMF Working Papers describe research in progress by the author(s) and are published to elicit comments and to encourage debate. The views expressed in IMF Working Papers are those of the author(s) and do not necessarily represent the views of the IMF, its Executive Board, or IMF management.

$$
\text { I N T E R N A T I O N A L M O N E T A R Y F U N D }
$$




\title{
IMF Working Paper
}

Western Hemisphere Department

The Macroeconomic Impact of Social Unrest

Prepared by Metodij Hadzi-Vaskov, Samuel Pienknagura and Luca Antonio Ricci ${ }^{1}$

May 2021

\begin{abstract}
IMF Working Papers describe research in progress by the author(s) and are published to elicit comments and to encourage debate. The views expressed in IMF Working Papers are those of the author(s) and do not necessarily represent the views of the IMF, its Executive Board, or IMF management.
\end{abstract}

\begin{abstract}
This paper explores the macroeconomic impact of social unrest, using a novel index based on news reports. The findings are threefold. First, unrest has an adverse effect on economic activity, with GDP remaining on average 0.2 percentage points below the pre-shock baseline six quarters after a one-standard deviation increase in the unrest index. This is driven by sharp contractions in manufacturing and services (sectoral dimension), and consumption (demand dimension). Second, unrest lowers confidence and raise s uncertainty; however, its adverse effect on GDP can be mitigated by strong institutions and by a country's policy space. Third, an unrest "event", which is captured by a large change in the unrest index, is associated with a 1 percentage point reduction in GDP six quarters after the event. Impacts differ by type of event: episodes motivated by socio-economic reasons result in sharper GDP contractions compared to those associated with politics/elections, and events triggered by a combination of both factors lead to sharpest contractions. Results are not driven by countries with adverse growth trajectories prior to unrest events or by fiscal consolidations, and are robust to instrumenting via regional unrest.
\end{abstract}

JEL Classification Numbers: D74; F50; O11; O47

Keywords: Social unrest, Economic activity, Growth; Institutions, Policy space

Authors’ E-Mail Addresses: MHadziVaskov@imf.org; SPienknagura@imf.org; LRicci@imf.org

\footnotetext{
${ }^{1}$ We thank Philip Ba rrettfor kindly sharing the social unrest data and for valuable comments. The paper also benefitted from helpful comments by Elena Ianchovichina, Deniz Igan, Inci Otker, Martín Rama, Daniel Riera-Crichton, Guillermo Vuletin, and participants at the IMF WHD Seminar and the World Bank LAC Chief Economist Office Seminar.
} 


\section{Contents}

I. Introduction

II. Literature And Motivation ___________________________________________________-_ 4

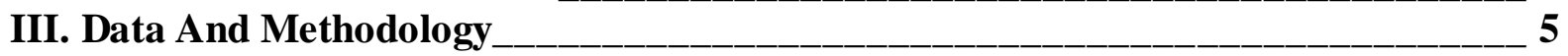

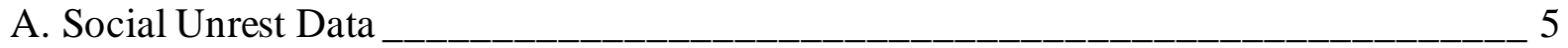

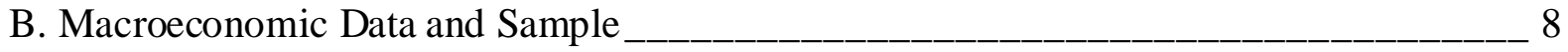

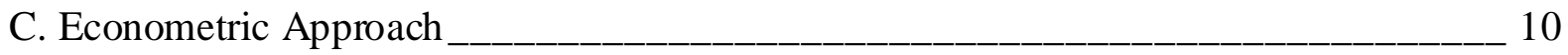

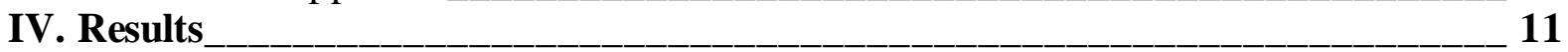

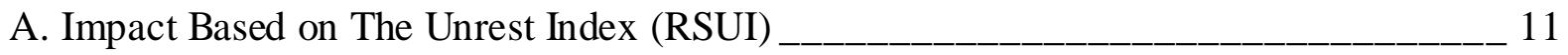

B. Role of Institutions and Policy Space __________________________________________ 14

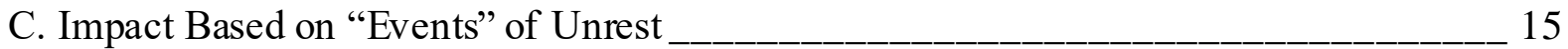

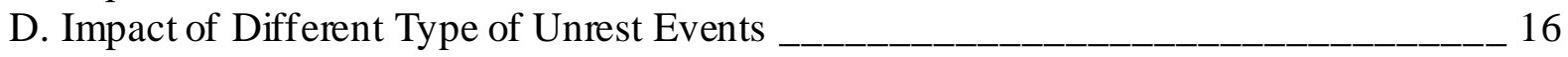

E. Addressing Reverse Causality and Endogeneity Concerns __________________________ 17

V. Conclusions ___________________ 25

\section{Figures}

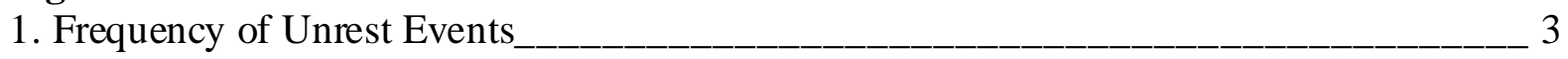

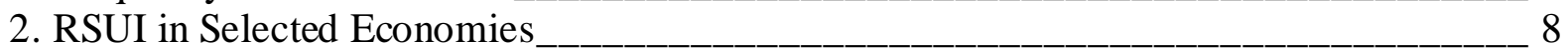

3. Impact of Social Unrest on GDP _____________________________________________ 12

4. Impact of Social Unrest on Economic Sectors _________________________________- 13

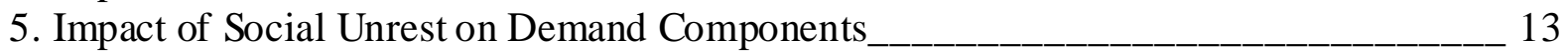

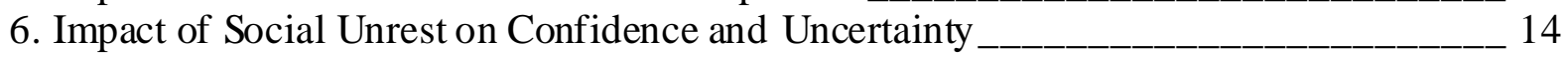

7. Impact of Social Unrest on GDP Across Country Groups _________________-_________ 14

8. Impact of Social Unrest Conditional on Institutions and Policy Space________________ 15

9. Impact of RSUI-implied Unrest Events on GDP________________________________ 16

10. Impact of Different Types of Events on GDP

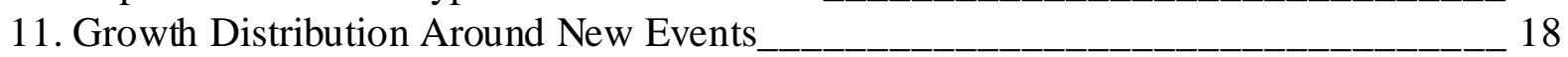

12. Impact of Social Unrest on GDP After Con trolling for Prior Adverse Growth Events

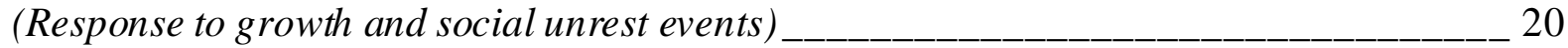

13. Impact of Social Unrest on GDP After Controlling for Prior Adverse Growth Events

(Response to a one st.dev. shock to the RSUI) ______________________________________-_ 21

14. Impact of Social Unrest on GDP After Controlling for Fiscal Consolidations ________ 22

15. Impact of Social Unrest on GDP, Instrumental Variables Approach (Response to a one

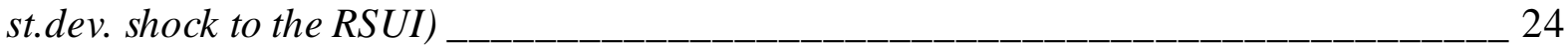

16. Impact of Social Unrest on GDP, Instrumental Variables Approach (Response to a new

RSUI-Implied event) ______________________________________________________________ 25

Tables

1. Article Search Criteria____-_-_-_-_-_-_-_-_-_-_-_-_-_-_-_-_-_-_-_-_-_-_-_-_-_-_-_-_ 6

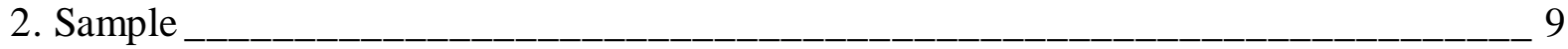

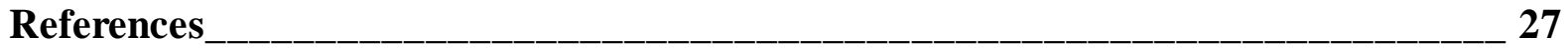

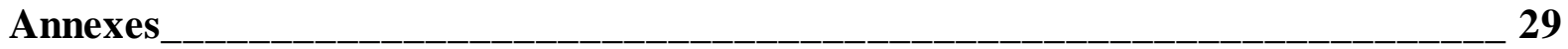

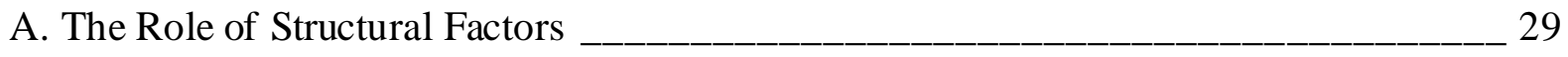

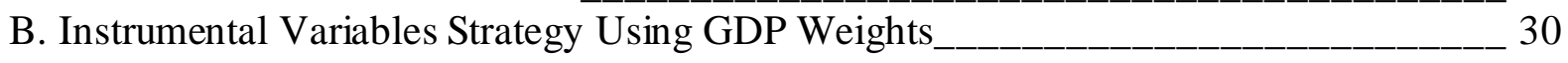




\section{INTRODUCTION}

The frequency of social unrest has increased recently (Figure 1), with important social political, and economic ramifications across the globe. Only in 2019, social unrest events have affected a diverse set of countries, ranging from advanced economies (France and the People's Republic of China Hong Kong Special Administrative Region) to emerging market economies (Chile and Lebanon). The latest Global Peace Index (2020) suggests that the number of riots, general strikes and anti-government demonstrations around the world increased by 244 per cent over the last decade (2011 to 2019). Importantly, these unrest events have affected the lives and livelihoods of millions of persons around the world.

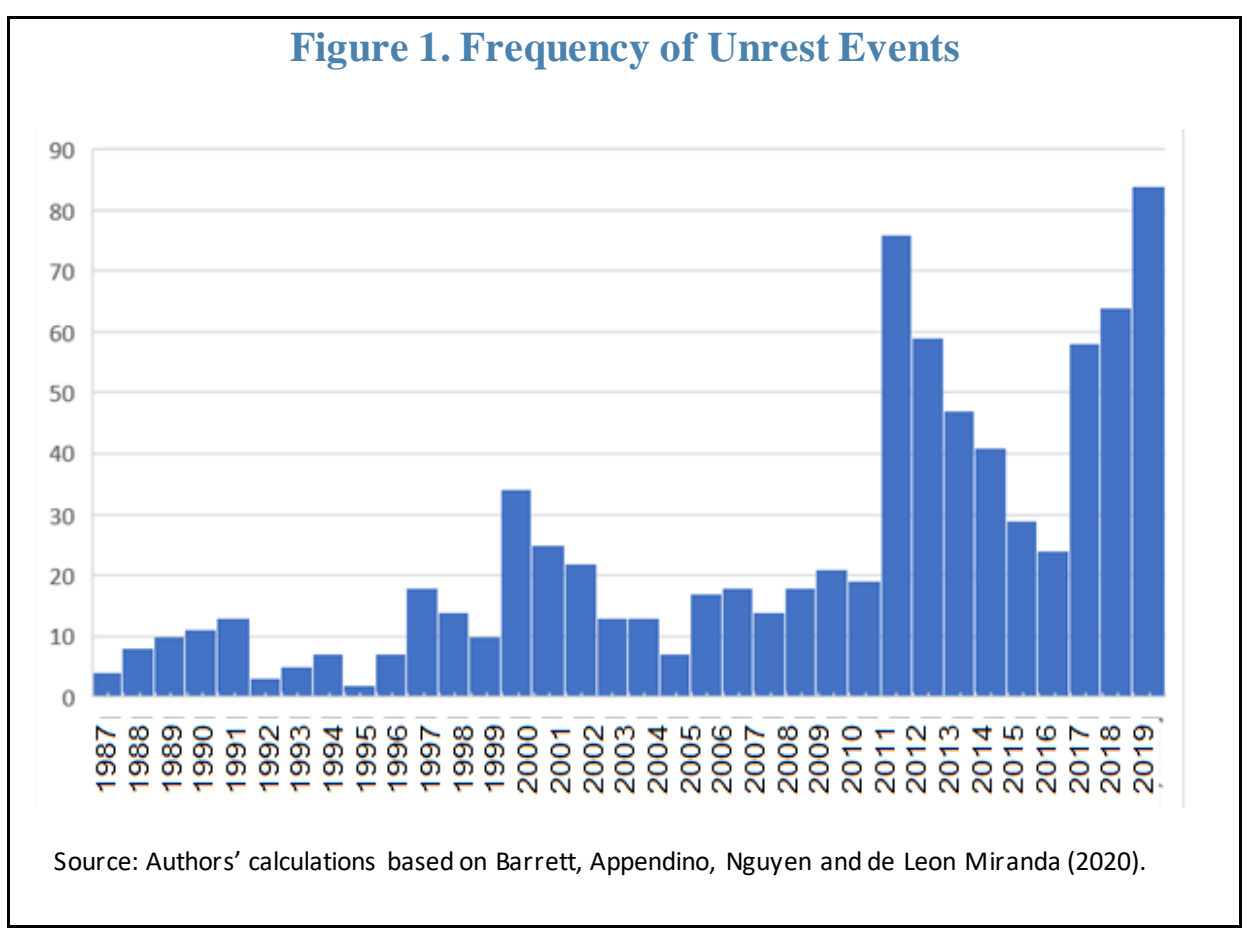

Recent trends could be further accentuated by the COVID-19 pandemic (Barrett and Chen, 2021). The Coronavirus crisis is having profound health and socio-economic implications across various groups in society. Nonetheless, its adverse impact appears particularly concentrated among the most vulnerable segments of the population. In this context, recent studies find that the pandemic could exacerbate inequality and poverty (Furceri, Loungani, Ostry, and Pizzuto, 2020; IMF, 2020). Thus, to the extent that these socio-economic variables are important drivers of popular discontent, social unrest could be further fueled by the pandemic.

In light of these concerns, this study explores the macroeconomic impact of social unrest episodes. In particular, it addresses the following questions: How does social unrest affect economic activity? What sectors and components of aggregate demand are more likely to be adversely affected? Can the adverse economic implications of social unrest be dampened by strong institutions and available policy space? Are emerging markets and advanced economies affected similarly? Do different types of unrest have different effects? 


\section{LITERATURE AND MOTIVATION}

Studies of the macroeconomic effects of social unrest are generally limited, with more focus in the literature commonly placed on large, violent, conflicts. For instance, some studies have found that conflicts are a key hurdle to economic growth (Rodrik, 1999), produce persistent negative effects on output (Cerra and Saxena, 2008; IMF, 2019; Rother et al. 2016), and result in large overall macroeconomic costs (Novta and Pugacheva, 2020). In this context, a related strand of the literature looks at the impact of political instability on economic performance, considering social unrest as an element that negatively affects growth (Alesina et al. 1996; Aisen and Veiga, 2013; Jong-A-Pin, 2009).

The pickup in episodes of social unrest around the globe in recent years has raised the interest in understanding the causes and consequences of these events, including through recent work at the IMF. For instance, Barrett et al. (2021) investigate the effects of social unrest on stock markets across the world. Hlatshwayo and Redl (forthcoming) examine the macro-criticality of social unrest and use machine-learning techniques to forecast future unrest. Saadi Sedik and Xu (2020) investigate the dynamics among social unrest, major pandemic in history, economic growth, and inequality.

This paper contributes to the growing literature studying the economic impact of social unrest by leveraging on the novel index constructed by Barrett, Appendino, Nguyen and de Leon Miranda (2020). The index provides a timely, transparent, and high-frequency indicator with broad and consistent cross-country coverage based on counts in relevant media reports. Compared to existing indicators, it provides higher frequency (than the Cross-National Time-Series Data-CNTD, annual), broader coverage (than the Armed Conflict Location and Event Database - ACLED, mainly focused on SSA) and more objectivity and replicability (than International Country Risk Guide - ICRG, which relies on subjective assessment).

Using this novel index, the paper applies the local projection method proposed by Jordà (2005) and Teulings and Zubanov (2014) to investigate the macroeconomic impact of social unrest considering: i) a broad pool of social events, including those less severe than civil conflicts (compared to the literature looking at the economic costs of conflicts); ii) the impact on higher frequency economic indicators (compared to most studies that focus on annual data); and iii) the impact on various demand-side and supply-side components, with the aim to better understand the underlying channels through which unrest is adversely affecting economic activity.

The results point to sizeable economic costs associated with episodes of social unrest, but the effects depend on country characteristics and on the nature of the event. On average, economic activity declines following spikes in the unrest index. The adverse effect of unrest on GDP is driven by contractions in manufacturing and services value added (sectoral dimension), and consumption (demand dimension). The findings suggest that one channel through which social unrest affects activity is by lowering confidence and by increasing uncertainty. The results also highlight the role played by institutions and policy space as mitigating factors - countries with strong institutions and ample policy space have more modest declines in activity following episodes of unrest. The economic impact of unrest also differs by type of events: episodes motivated by socio-economic reasons result in sharper 
GDP contractions compared to those associated mainly with politics/elections, while unrest triggered by a combination of both socio-economic and political issues sees sharpest contractions.

Moreover, the results are robust to reverse causality and omitted variables concerns. Episodes of social unrest lead to lower economic activity both in countries that faced low growth prior to social unrest as well as those that experienced above average growth pre-event. However, the economic impact of unrest is larger in countries that experienced adverse growth trajectories prior to social unrest, suggesting that unrest compounds the impact of low growth fundamentals. Furthermore, results do not appear to be driven by the fact that fiscal consolidations can simultaneously trigger economic contractions and social unrest - GDP systematically declines both in countries that experience sizeable and swift improvements in the primary deficits and those that do not. Finally, results are robust to instrumenting social unrest with regional waves of social unrest.

\section{Data And Methodology}

\section{A. Social Unrest Data}

\section{Reported Social Unrest Index (RSUI)}

Social unrest data comes from Barrett, Appendino, Nguyen and de Leon Miranda (2020). They propose the reported social unrest index (RSUI), a monthly news-based index starting in January 1985 that quantifies the extent of social unrest for a large set of countries. The primary source for news articles is Dow Jones' Factiva news aggregator. The sample used in the compilation of the index is restricted to printed articles published in major Englishlanguage newspapers and networks in Canada, the UK and the US.

The RSUI takes the following form:

$$
R S U I_{i t}^{A}=\frac{x_{i t}}{\frac{1}{12} \sum_{j=1}^{12} z_{t-j}} \times \frac{100}{\bar{x}_{i} / \bar{z}}
$$

where $x_{i t}$ is the article count related to unrest in country $i$ in month $t ; z_{t}$ is the overall article count in period $t$; and $\bar{x}_{i}$ and $\bar{z}$ are the corresponding averages over all time periods.

In order to obtain the article counts used in the construction of the RSUI, Barrett et al. (2020) employ a set of search criteria (Table 1). The search criteria for determining the article count related to unrest in a specific country at a given month are complex and include both inclusive and exclusive requirements. In particular, the inclusive requirements aim to select language related to unrest, such as protests, riots, revolutions, and other forms of civil or domestic unrest. The exclusive requirements aim to avoid false positives by omitting articles that contain words that may erroneously be associated with unrest or may be related to anniversaries of previous unrest episodes. In addition, the location criteria ensure that the article refers to social unrest directed at a specific country, and the word count ensures a 
minimum threshold of 100 words for articles to be included. The RSUI measures the extent of social unrest for each country over time relative to its country mean. The cross-sectional properties of the RSUI are described in detail in Barrett et al. (2020).

\begin{tabular}{|c|c|c|c|}
\hline \multicolumn{4}{|c|}{ Table 1. Article Search Criteria } \\
\hline & $x_{i t}$ & $y_{i t}$ & $z_{t}$ \\
\hline Must include & $\begin{array}{l}\text { Country name AND ("protest*" OR "riot*" OR } \\
\text { "revolution" OR (("civil" or "domestic") within } 10 \\
\text { words of "unrest") }\end{array}$ & $\begin{array}{l}\text { Country } \\
\text { Name AND } \\
\text { "today" }\end{array}$ & "today" \\
\hline Must exclude & $\begin{array}{l}\text { Country-specific terms OR "vote of protest" OR } \\
\text { "protest vote" OR "protestant*" OR "anniversary" } \\
\text { OR "war" OR "memorial" OR "movie" }\end{array}$ & & \\
\hline Location tag & Country $i$ & Country $i$ & \\
\hline Subject tag & Domestic Politics Or Civil Unrest & & \\
\hline Word count & $100+$ & $100+$ & $100+$ \\
\hline
\end{tabular}

\section{RSUI-implied Events}

In addition to constructing the index, Barrett et al. (2020) propose an algorithm to identify RSUI-implied events. Such an event has to satisfy the following three criteria:

1. It must be a local peak: $R S U I_{i t}=\max \left\{R S U I_{i t+1}, R S U I_{i t-1}\right\}$

2. The index must be large enough to satisfy one of the following conditions:

- $R S U I_{i t}>\overline{R S U I_{i t}}+\left(4 * s d\left(R S U I_{i t}\right)\right)$ or

- $R S U I_{i t}$ is in the top $2 \%$ or

- $R S U I_{i t}$ exceed the 20 -year moving average by 4 times the 20-year st. dev.

3. The unrest article count for the month is at least 10 percent the average monthly count for the country over the past 12 months.

Importantly, the authors also construct detailed event timelines from independent narrative sources for more than a dozen country-specific case studies, showing that these detailed events line up closely with RSUI-implied events. They thus conclude that large changes in reported unrest are driven by highly newsworthy, real-world events rather than mismatches, changes in media focus, bias, or other sources of error.

In addition to these RSUI-implied events, we label an event that is satisfying all five criteria as a major event. 


\section{Unrest Data Used in the Analysis}

In the empirical analysis, we use the RSUI series and apply several transformations of the monthly data, as follows.

- First, for each country, we aggregate the RSUI at the quarterly level by taking the maximum monthly level of the RSUI over the corresponding quarter. In this way, we aim to ensure that a (local) spike in social unrest is reflected in the quarterly series.

- Second, we also aggregate the RSUI-implied event dummy constructed by the authors and the additional major event dummy at the quarterly level (taking the maximum over the quarter). Notably, we focus on new events - events that are at least 8 quarters apart from each other. In the analysis, we use both the RSUI index and the identified events, in separate exercises.

- Third, we further categorize the events into three types (political/elections, socioeconomic, or mixed), by consulting contemporaneous news articles and reports to better understand the underlying causes and triggers of all events that could be identified. In particular, using contemporaneous news reports, we identify keywords associated with the events. We use those keywords to determine the triggers of the events in our dataset. While certain degree of judgement is necessarily involved and unavoidable in such exercises, we aim to reflect the broadest available evidence that can be found for certain identified social unrest event in the public sources. Based on the event's main underlying cause/trigger, we distinguish between 3 types of events:

a) Political/elections;

b) Socio-economic;

c) Mixed (intrinsically intertwined political and socio-economic causes).

- all remaining events for which we could not clearly identify the underlying reasons as political, economic or mixed are included in a residual category of "events that cannot be labeled". In total, we categorize 490 events as having political/elections as the dominant underlying reasons, 101 socio-economic, 40 mixed political and economic reasons, and the underlying reasons for the remaining 205 events could not be clearly identified.

Figure 2 shows the evolution of the RSUI for the selected set of economies affected by social unrest in 2019 that were mentioned in the introduction. The quarterly value of RSUI is defined by the maximum of the original monthly RSUI over the 3 months of that quarter. It is important to note that the value of the RSUI should be compared relative to the countryspecific distribution and is not intended to capture the severity of unrest. For example, the recent spike of the RSUI for Chile to 4,000 in 2019 suggests that the unrest event was an extreme event given Chile's RSUI distribution over the past $31 / 2$ decades, but does not imply that the event was more severe than the spikes in France and Lebanon, or less severe than the one in Hong Kong SAR. However, as shown in Barret et al. (2020), there are cross-sectional properties of the distribution of the RSUI, which maps a country's RSUI level to its position in the cross-sectional distribution. 


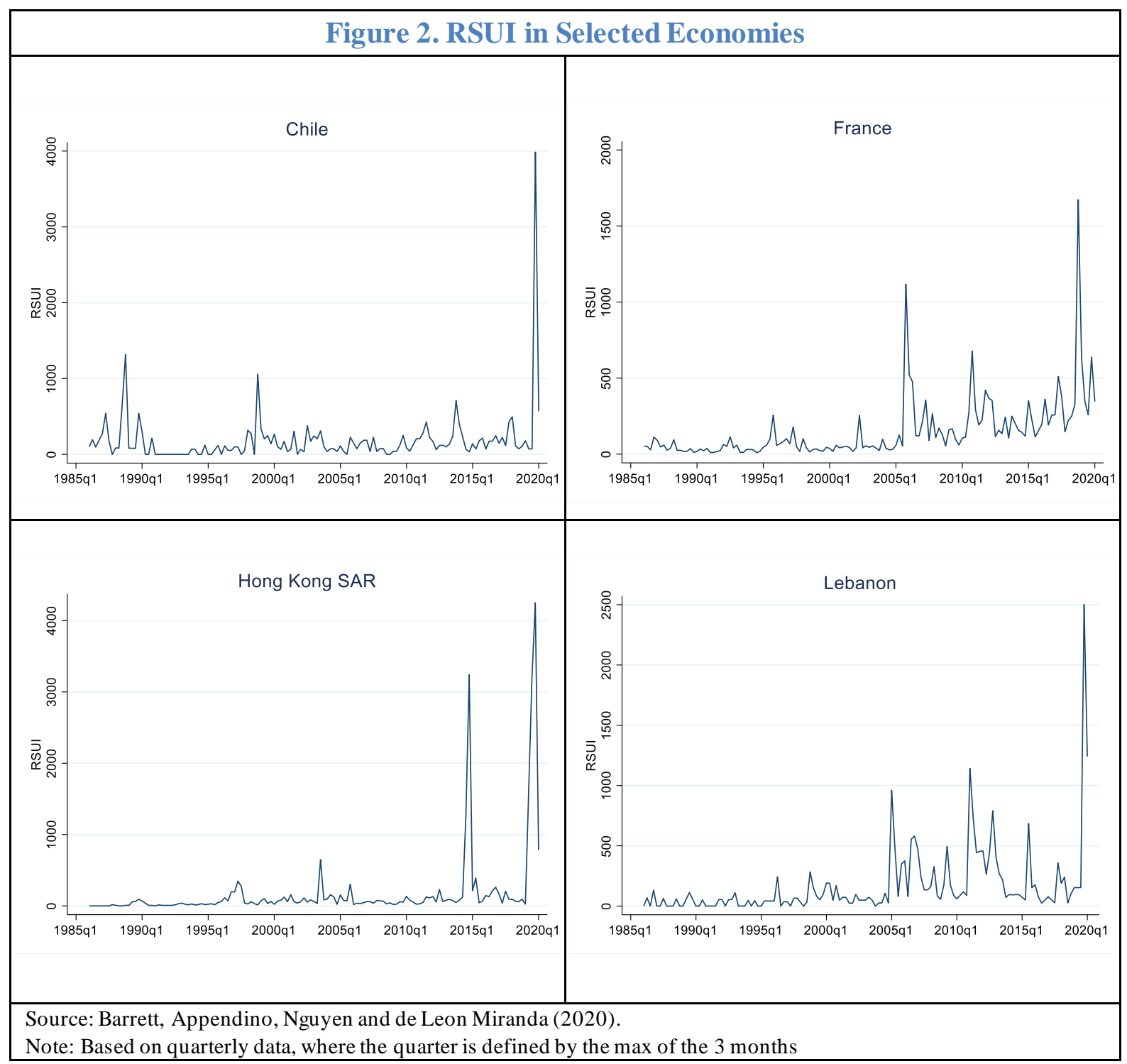

\section{B. Macroeconomic Data and Sample}

We include all 89 countries for which RSUI, quarterly GDP, and commodity terms-of-trade data are available over the period 1990-2019 (Table 2). We exclude fragile states - those labeled as fragile states by the World Bank in at least one year since 2006 - in order to avoid our results being driven by countries in enduringly fragile social conditions or facing prolonged episodes of violence.

We collect quarterly GDP and other national accounts data from national sources (seasonally adjusted by authorities if available, otherwise we use Haver for seasonal adjustment). Data series on debt-to-GDP come from the Fiscal Monitor database. Rule of law estimates come from the World Governance Indicators (Kaufmann, Kraay, and Mastruzzi, 2010), and data on exchange rate regimes comes from Ilzetzki, Reinhart and Rogoff (2019). We retrieved data series for confidence indicators from Haver. Data on uncertainty comes from the latest vintage of the World Uncertainty Index proposed by Ahir, Bloom and Furceri (2018). 
Commodity terms-of-trade data comes from Gruss and Kebhaj (2019). Data on bilateral distance and contiguity used in Section E comes from CEPII's Geodist dataset. Data on labor market legislation comes from ILO's EPLEX dataset. Data on primary balances comes from the IMF's World Economic Outlook dataset. Finally, data on product market competition comes from the Global Competitive Index compiled by the World Economic Forum.

\begin{tabular}{|c|c|}
\hline \multicolumn{2}{|c|}{ Table 2. Sample } \\
\hline 32 Advanced Economies & $\begin{array}{l}57 \text { Emerging Markets and } \\
\text { Low-Income Countries }\end{array}$ \\
\hline $\begin{array}{c}\text { Australia (1990Q1-2019Q4), Austria } \\
\text { (1996Q1-2019Q4), Belgium (1995Q1- } \\
\text { 2019Q4), Canada (1990Q1-2019Q4), Cyprus } \\
\text { (1995Q1-2019Q4), Czech Republic (1996Q1- } \\
\text { 2019Q4), Denmark (1990Q1-2019Q4), } \\
\text { Estonia (1995Q1-2019Q4), Finland (1990Q1- } \\
\text { 2019Q4), France (1990Q1-2019Q4), } \\
\text { Germany (1990Q1-2019Q4), Greece } \\
\text { (1995Q1-2019Q4), Hong Kong SAR } \\
\text { (1990Q1-2019Q4), Ireland (1995Q1-2019Q4), } \\
\text { Israel (1995Q1-2019Q4), Italy (1990Q1- } \\
\text { 2019Q4), Japan (1990Q1-2019Q4), Korea } \\
\text { (1990Q1-2019Q4), Latvia (1995Q1-2019Q4), } \\
\text { Lithuania (1995Q1-2019Q4), Netherlands } \\
\text { (1990Q1-2019Q4), New Zealand (1990Q1- } \\
\text { 2019Q4), Norway (1990Q1-2019Q4), } \\
\text { Portugal (1995Q1-2019Q4), Singapore } \\
\text { (1990Q1-2019Q4), Slovakia (1995Q1- } \\
\text { 2019Q4), Slovenia (1995Q1-2019Q4), Spain } \\
\text { (1995Q1-2019Q4), Sweden (1990Q1- } \\
\text { 2019Q4), Switzerland (1990Q1-2019Q4), UK } \\
\text { (1990Q1-2019Q4), United States (1990Q1- } \\
\text { 2019Q4) }\end{array}$ & $\begin{array}{l}\text { Albania (2008Q1-2019Q4), Argentina (1990Q1- } \\
\text { 2019Q4), Azerbaijan (2001Q1-2019Q4), Bahrain } \\
\text { (2008Q1-2019Q4), Belarus (2009Q1-2019Q4), } \\
\text { Bolivia (1990Q1-2019Q4), Brazil (1990Q1- } \\
\text { 2019Q4), Bulgaria (1995Q1-2019Q4), Chile } \\
\text { (1990Q1-2019Q4), China (1992Q1-2019Q4), } \\
\text { Colombia (2000Q1-2019Q4), Croatia (2000Q1- } \\
\text { 2019Q4), Ecuador (1990Q1-2019Q4), Egypt } \\
\text { (2006Q3-2019Q4), Ghana (2006Q1-2019Q4), } \\
\text { Guatemala (2001Q1-2019Q4), Honduras } \\
\text { (2000Q1-2019Q4), Hungary (1995Q1-2019Q4), } \\
\text { India (1996Q2-2019Q4),Indonesia (1990Q1- } \\
\text { 2019Q4), Iran (2004Q2-2019Q4),Jordan } \\
\text { (1992Q1-2019Q4), Kazakhstan (1999Q1- } \\
\text { 2019Q4), Kenya (2009Q1-2019Q4), Kuwait } \\
\text { (2010Q1-2019Q4), Kyrgyz Republic (2012Q1- } \\
\text { 2019Q4), Macedonia (2000Q2-2018Q3), } \\
\text { Malaysia (1991Q1-2019Q4), Mexico(1990Q1- } \\
\text { 2019Q4), Moldova (2010Q1-2019Q4), } \\
\text { Montenegro (2011Q1-2019Q4), Morocco } \\
\text { (1998Q1-2019Q4), Nicaragua (2006Q1-2019Q4), } \\
\text { Panama (2007Q1-2019Q4), Paraguay (1995Q1- } \\
\text { 2019Q4), Peru (1990Q1-2019Q4), Philippines } \\
\text { (1990Q1-2019Q4), Poland (1995Q2-2019Q4), } \\
\text { Qatar (2010Q1-2019Q4), Romania (1995Q1- } \\
\text { 2019Q4), Russia (1995Q1-2019Q4), Rwanda } \\
\text { (2006Q1-2019Q4),Saudi Arabia (2010Q1- } \\
\text { 2019Q4), Senegal (2017Q1-2019Q4), Serbia } \\
\text { (1995Q1-2019Q4), South Africa(1990Q1- } \\
\text { 2019Q4), Sri Lanka (2010Q1-2019Q4), Tanzania } \\
\text { (2010Q1-2019Q3), Thailand (1993Q1-2019Q4), } \\
\text { Tunisia (2000Q1-2019Q4), Turkey (1990Q1- } \\
\text { 2019Q4), Uganda (2008Q1-2019Q4), Ukraine } \\
\text { (2001Q1-2019Q4), United Arab Emirates } \\
\text { (2012Q1-2019Q4),Venezuela(1997Q1- } \\
\text { 2018Q4),Vietnam (2008Q4-2019Q4),Zambia } \\
\text { (2013Q1-2019Q3) }\end{array}$ \\
\hline
\end{tabular}




\section{Econometric Approach}

\section{Local Projection Method}

We assess the macroeconomic impact of episodes of social unrest using the local projection method proposed by Jordà (2005) and Teulings and Zubanov (2014). This method has the advantage that it does not constrain the shape of the impulse response functions and is less sensitive to misspecification than estimates of VAR models. The benchmark specification at a quarterly frequency is as follows:

$$
y_{i, t+h}-y_{i, t-1}=\alpha_{i}^{h}+\gamma_{t}^{h}+\sum_{j=1}^{h} \mu^{j, h} \text { unrest }_{i, t+j}+\beta^{h} \text { unrest }_{i, t}+\theta X_{i, t}+\varepsilon_{i, t+h}
$$

where $y$ is the variable of interest (GDP, sectoral value added, demand components, confidence); unrest is either the index proposed by Barrett et al. (2020) (RSUI) or the event dummy; $\alpha_{i}^{h}$ are country fixed effects, $\gamma_{t}^{h}$ are quarter/year fixed effects, and X are a set of controls that includes past values of the dependent variable, past values of terms-of-trade growth, and past values of the RSUI. As proposed by Teulings and Zubanov (2014), we

include the term $\sum_{j=1}^{h} \mu^{j, h}$ unrest $_{i, t+j}$ to control for the fact that unrest events may be persistent. Excluding this term could bias our estimates of $\beta^{h}$, which is our parameter of interest.

One potential caveat of a causal interpretation of the econometric approach described above is the potential reverse causality running from growth performance to social unrest and the potential omitted variable bias. We tackle the se concerns in three distinct ways. First. we distinguish between countries that faced negative growth events prior to the social unrest and those that did not. Second, we distinguish between countries that went through episodes of fiscal consolidation, events that have been linked to GDP contractions and social unrest. Finally, we implement an IV approach that exploits regional waves of social unrest. More details are presented later in the paper.

\section{State-dependent Local Projection}

In addition to the benchmark regression presented previously, we explore specifications that condition the response of activity to social unrest shocks to particular states $S$. Indeed, one of the main advantages of the local projection method in estimating the effects of shocks is its flexibility in dealing with non-linearities and state dependency (Ramey and Zubairy, 2018). Hence, the typical specification of the regression equation with state-dependent variables takes the following form:

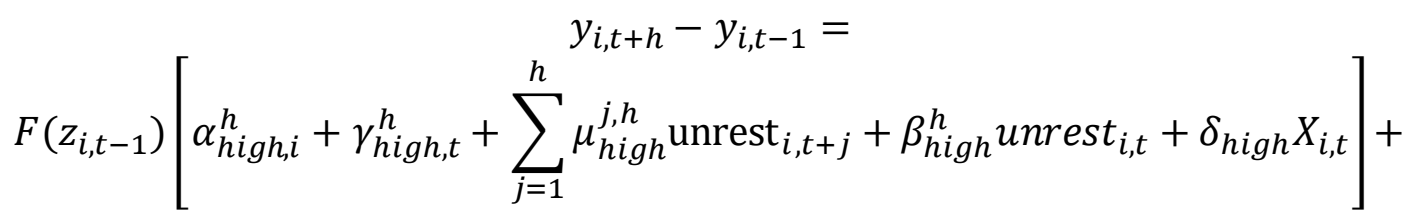




$$
\begin{gathered}
+\left(1-F\left(z_{i, t-1}\right)\right)\left[\alpha_{\text {low }, i}^{h}+\gamma_{\text {low }, t}^{h}+\sum_{j=1}^{h} \mu_{\text {low }}^{j, h} \text { unrest }_{i, t+j}+\beta_{\text {low }}^{h} \text { unrest }_{i, t}+\delta_{\text {low }} X_{i, t}\right] \\
+\varepsilon_{i, t+h .} \text { (2) }
\end{gathered}
$$

where $F\left(z_{i, t-1}\right)$ is a smooth function of the state variable taking a value between 0 and 1 ; and $\mathrm{z}$ is a normalized version of the state variable such that $F(0)=\frac{1}{2}$. In this analysis we are primarily interested in state variables that reflect the economies' institutional and policy settings. Hence, the state variables account for:
a) Rule of law
b) Debt level
c) Exchange rate flexibility
d) Labor market flexibility
e) Product market competition

In particular, each of the state variables are normalized such that the standardized variables (z) have mean zero and a standard deviation equal to 1 . In the case of exchange rate flexibility, $\mathrm{F}(\mathrm{z})$ is an indicator function that takes value one if the "fine" exchange rate classification constructed by Ilzetzki, Reinhart, and Rogoff (2019) takes a value higher than $9^{2}$, and zero otherwise. In turn, as is common in the literature, we assume $F\left(z_{i, t-1}\right)=$ $\exp \left(-\lambda_{0} z_{i, t-1}\right) /\left(1+\exp \left(-\lambda_{0} z_{i, t-1}\right)\right)$, where $\lambda_{0}$ takes value 1.5 (as in Auerbach and Gorodnichenko, 2012). ${ }^{3}$

\section{RESUlts}

\section{A. Impact Based on The Unrest Index (RSUI)}

Figure 3 presents our baseline results of the impact of the RSUI on economic activity. It shows that GDP experiences a steady decline following a shock of one standard deviation in the RSUI. For the overall sample, GDP declines by over -0.15 percentage points qoq on impact. After 6 quarters, quarterly GDP remains about 0.2 percentage points below its preshock level.

How large of a shock corresponds to one standard deviation in RSUI? Our calculations suggest that a shock of one standard deviation is equivalent to the protests following the Peña Nieto election in 2012 or Chile's presidential election protests in 2013. For comparison, the protests of July 2019 in Hong Kong SAR and the yellow vest protests of 2018 in France resulted in an increase of 4 standard deviations in the RSUI, while the events of October/November 2019 in Chile resulted in an increase of RSUI of 10 standard deviations.

\footnotetext{
${ }^{2}$ A country with classification of 9 is one that has a "preannounced crawling band that is wider than or equal to +/-2 percent".

${ }^{3}$ Results are robust to alternative choices for $\lambda_{0}$.
} 


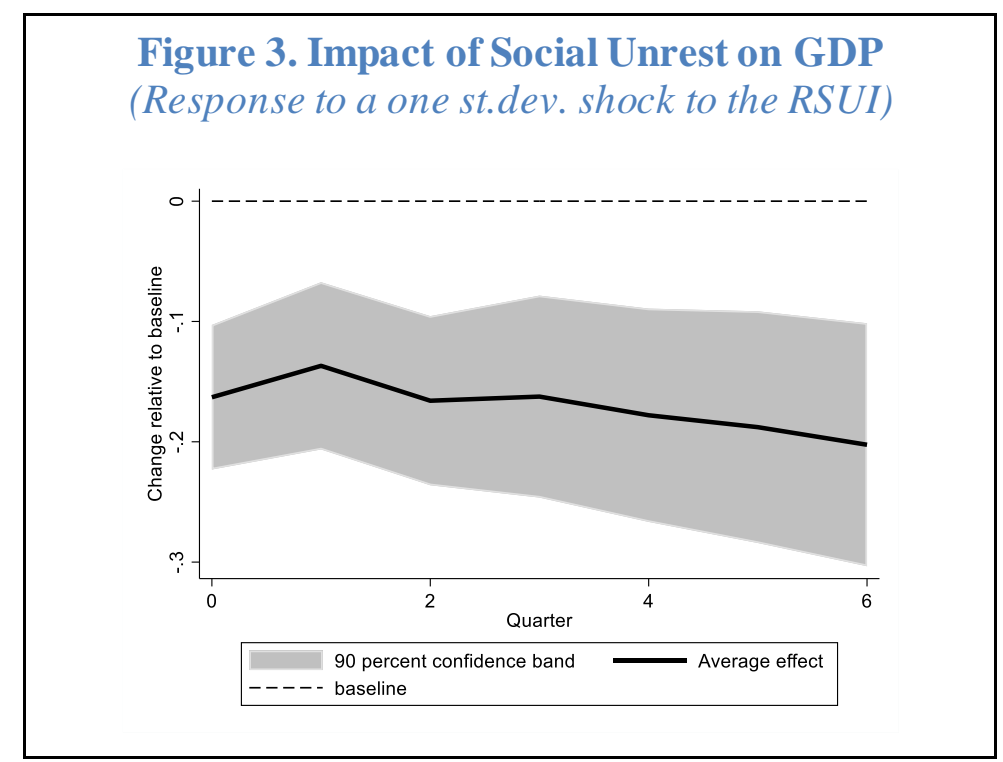

The assessment of the effect of shocks to the RSUI on aggregate economic activity may mask potential heterogeneity across sectors of the economy and across aggregate demand components. These differences may stem from the fact that episodes of social unrest may affect unevenly some areas (urban vs rural areas) or economic agents with distinct patterns of sectoral specialization and consumption. Understanding these differences may also provide a better understanding of the mechanics through which unrest affects aggregate growth and its potential impact on medium-term performance. Hence, in Figures 4 and 5 we present results for GDP's components from the sectoral/supply side and demand side, respectively.

On the one hand, Figure 4 shows that the adverse effects on GDP appear to be driven by sharp contractions in services and manufacturing. The effects after 6 quarters appear to be similar in magnitude across to the two sectors and slightly higher than for GDP (about 0.4 percentage points relative to baseline, respectively). However, the decline in services activity appears to be more immediate while that of manufacturing appears to be more gradual. On the other hand, the impact on agriculture is not significant at any point over the horizon. This result is not surprising given that social unrest is typically associated with larger urban centers and locations with higher concentration of services activity and manufacturing production, and thereby more likely to directly impede the normal functioning of these sectors; unless social unrests escalate and jeopardize the stability and security of the whole country, they are unlikely to pose commensurate obstacles to agriculture production. 
Figure 4. Impact of Social Unrest on Economic Sectors

(Response to a one st.dev. shock to the RSUI)

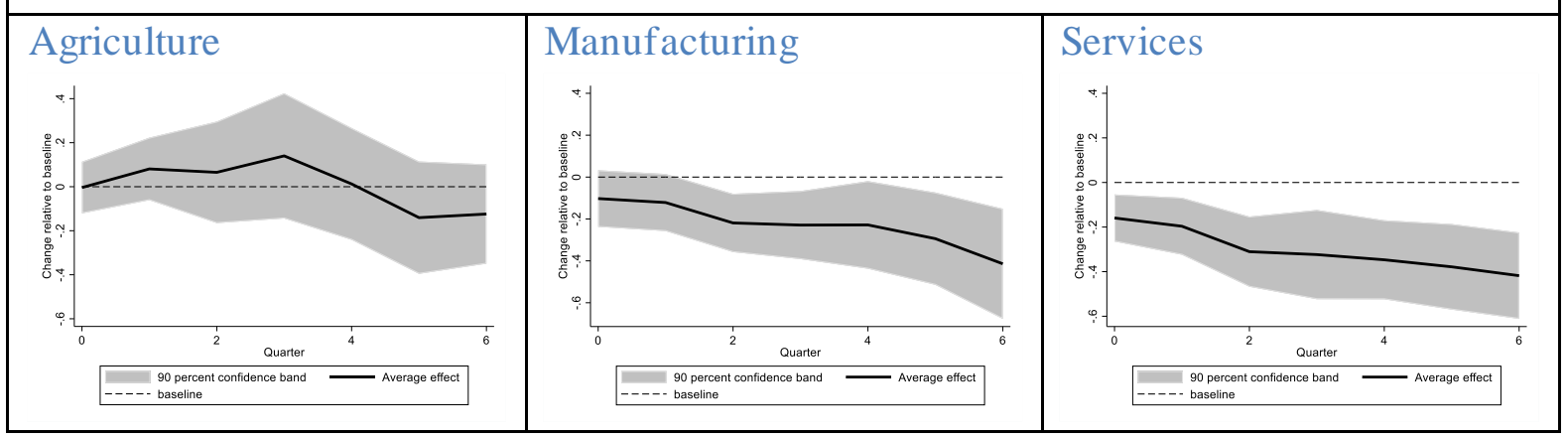

Turning to the demand-side components, Figure 5 shows that the effect of social unrest is more evident on consumption. The impact on consumption is negative and significant over most of the six quarters following the unrest shock. While the unrest shock seems to lower investment as well, this effect is not statistically significant. The difference in the response of consumption and investment suggests that the impact of social unrest is concentrated in the short-term and affects immediate decisions, while its effect on perturbating medium- to longterm expectations (critically important for investment) is more limited. Inevitably, however, average effects likely mask country-specific experiences, some of which may be characterized by substantial deteriorations of long-term expectations and sharper contractions of investment relative to consumption. Finally, both exports and imports fall following spikes in the social unrest index. However, the contraction in imports associated with the documented drop in consumption becomes larger after the initial shock relative to the contraction in exports, leading to an improvement of the trade balance.

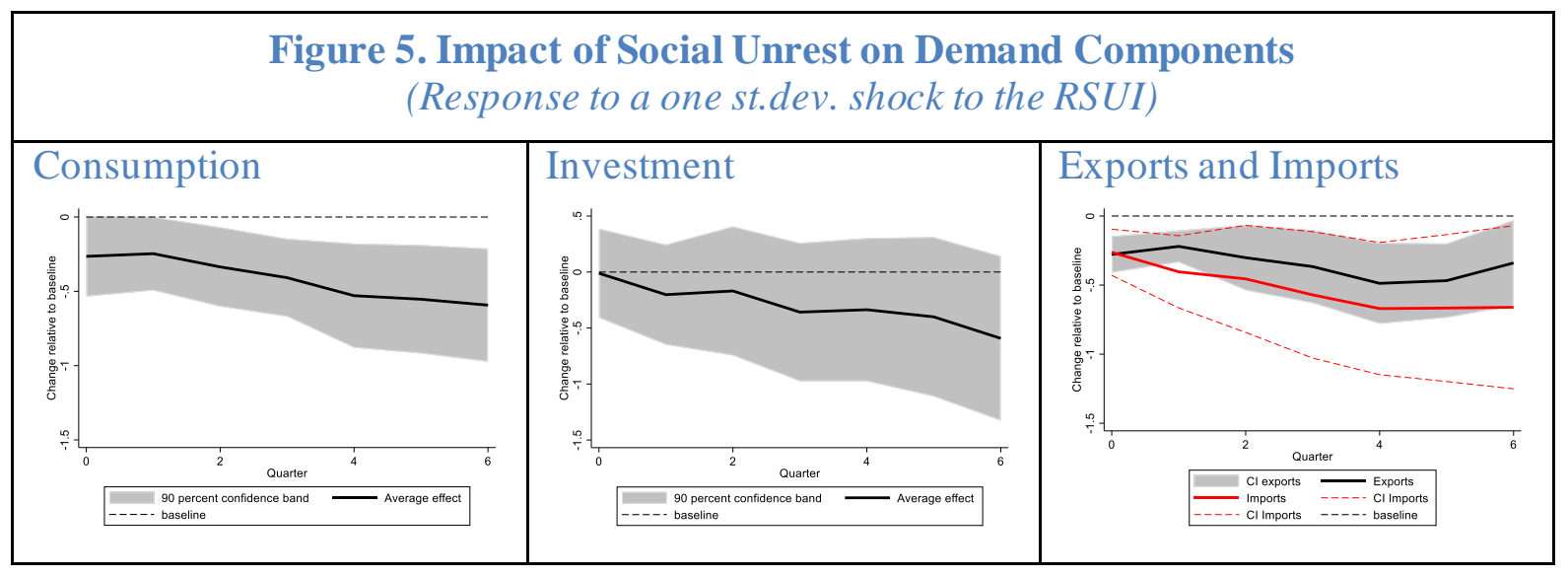

Figure 6 documents the impact of social unrest on uncertainty, consumer and business confidence. The left panel shows that the shock to RSUI is associated with a significant increase in the World Uncertainty Index for the corresponding economy for a few quarters, before dying out during the first year. In addition, social unrest is associated with a drop in consumer confidence, and to a lesser extent in business confidence, albeit these effects are generally not statistically significant. 


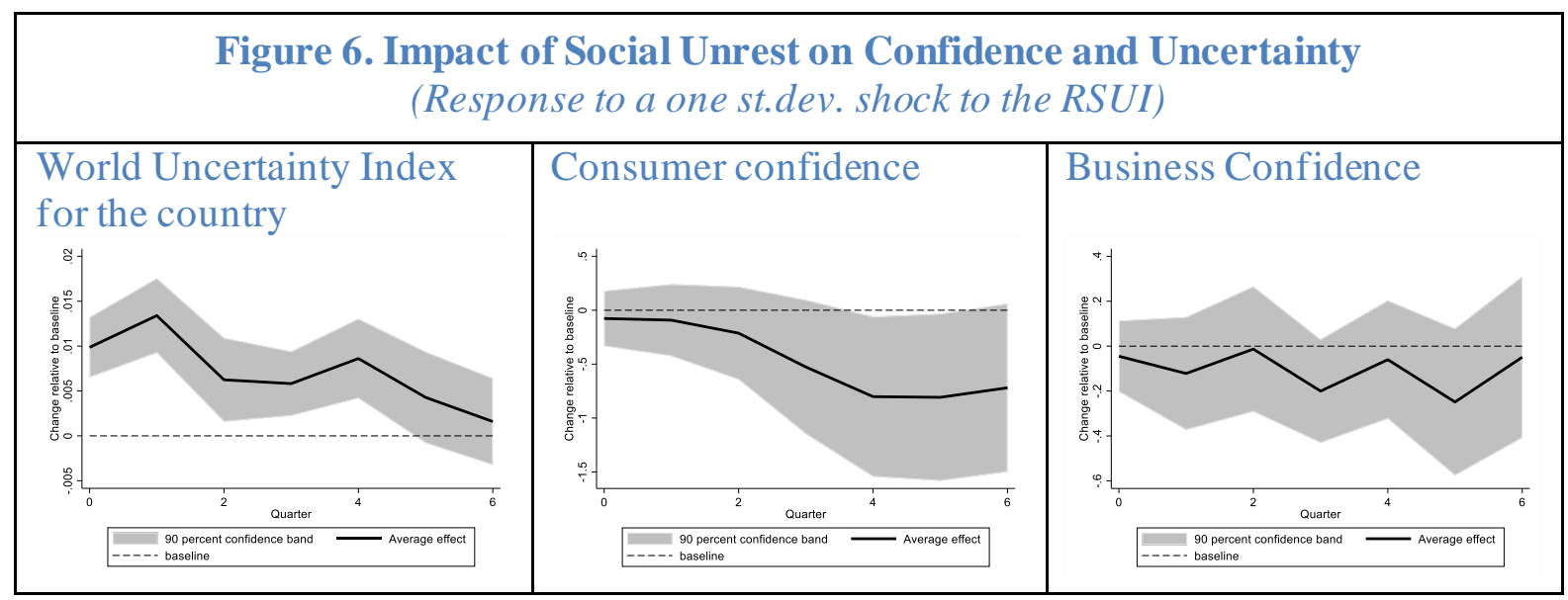

While the results so far have included all economies in our dataset, Figure 7 makes a distinction between advanced economies (AEs) and emerging markets and developing economies (EMDEs). The findings in Figure 7 suggest that the adverse effects of social unrest are evident in all countries regardless of income levels, but the effect is twice as large on impact in EMDEs relative to AEs, and remains somewhat larger throughout the window of analysis. Besides higher income levels, various other characteristics of AEs may help them better cushion the impact of social unrest, including the strength and maturity of their institutional and policy frameworks, which is possibly reflected in these results. We turn to formally analyzing such conjectures in the next section.

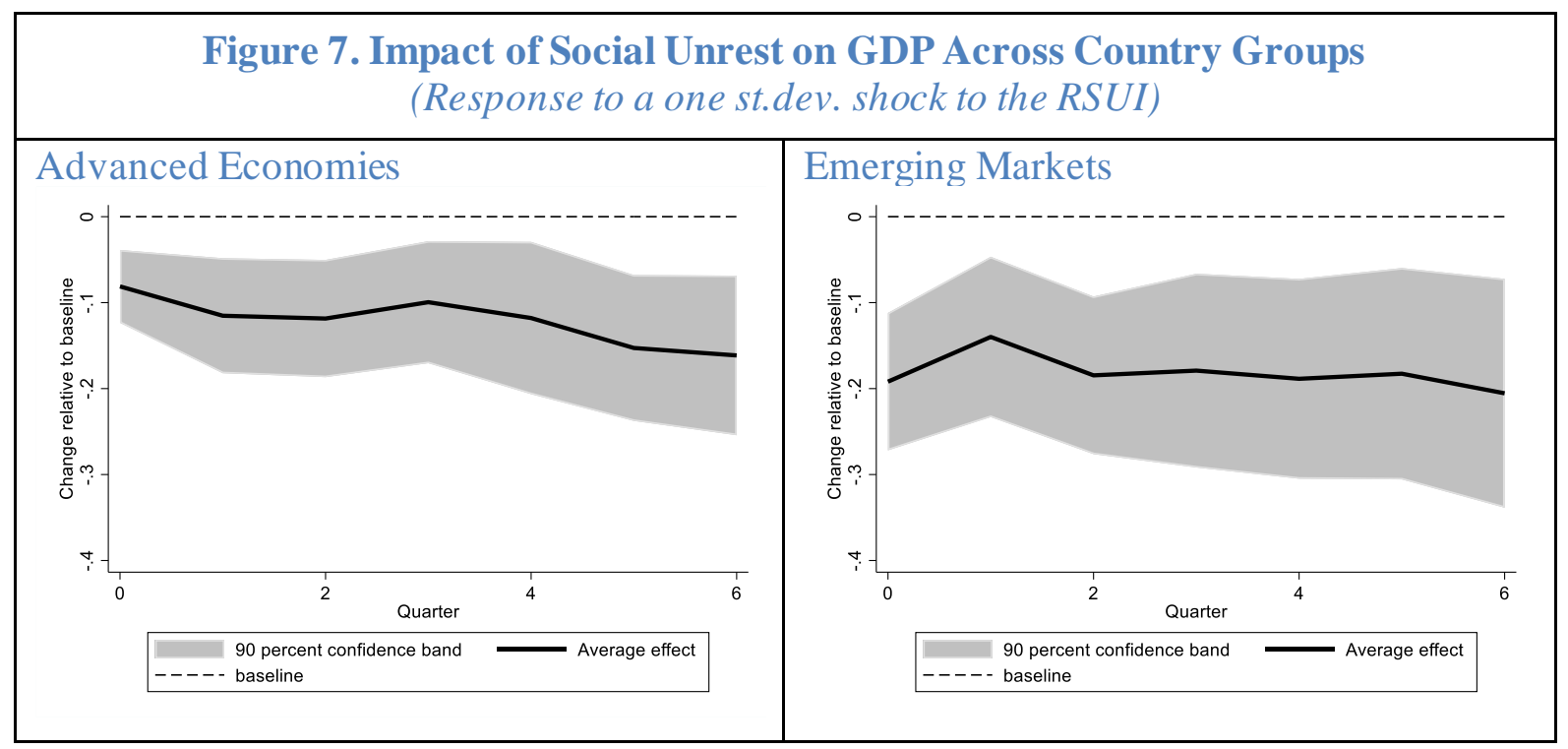

\section{B. Role of Institutions and Policy Space}

Figure 8 presents results assessing the role of institutional settings and policy space in mitigating the impact of social unrest on economic activity, based on the state-dependent local projections discussed above. Strong institutions - measured here by the level of rule of law-could play an important role in allowing a robust engagement of civil society, which is 
crucial in mature democracies, without leading to disproportionate economic costs (see Acemoglu and Robinson 2019). Similarly, having ample policy space may allow countries to buffer the direct economic impact of social unrest or to meet the demands posed by society.

Indeed, the result in Figure 8, left panel, shows that countries with strong institutions see no decline in activity in the aftermath of episodes of unrest relative to baseline. By contrast, countries with weak institutions experience a 0.4 percentage point decline in activity six quarters after episodes of unrest. Similarly, economies with ample policy space - measured by the public debt level and the degree of exchange rate flexibility - are found to better cope with the adverse impact of social unrest episodes.

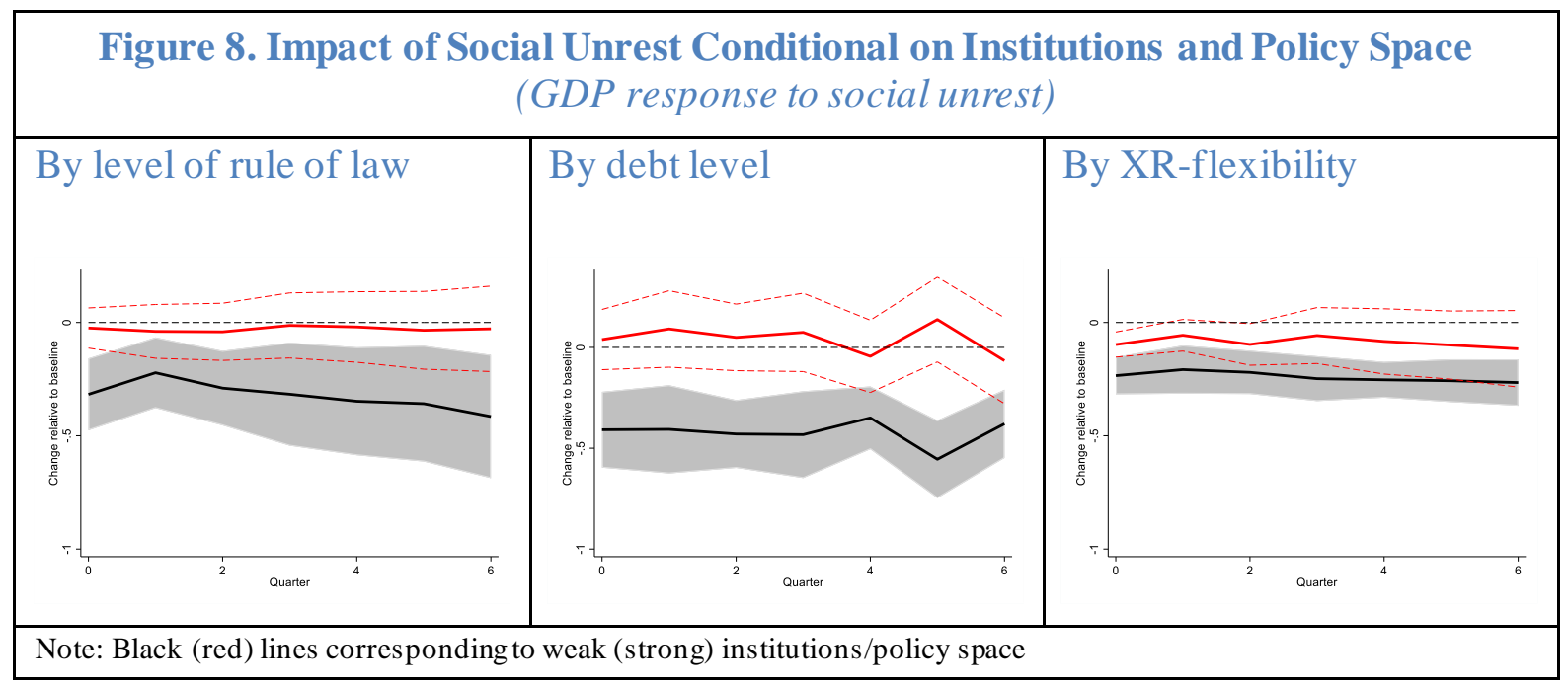

\section{Impact Based on "Events" of Unrest}

While the analysis so far has concentrated on unrest shocks as measured by the RSUI, this section explores the impact of RSUI-implied events, identified in line with the criteria explained in Section III.A. Accordingly, Figure 9 documents the impact of social unrest events on economic activity. We restrict the analysis to new (both overall and only major) events, according to the criteria presented in Section III.C, to distinguish these events from those that are part of a persistent wave of unrest.

We confirm that social unrest events exert a negative impact on GDP, and these effects are statistically significant. An RSUI-implied event lowers GDP by about $0.6 \mathrm{pp}$ on impact relative to baseline, and this effect grows to approximately $1 \mathrm{pp}$ after 1 year. Not surprisingly, major events lead to even larger GDP contractions. Moreover, similar as the results for shocks to the RSUI, these (major) unrest events have a persistent effect on economic activity. 


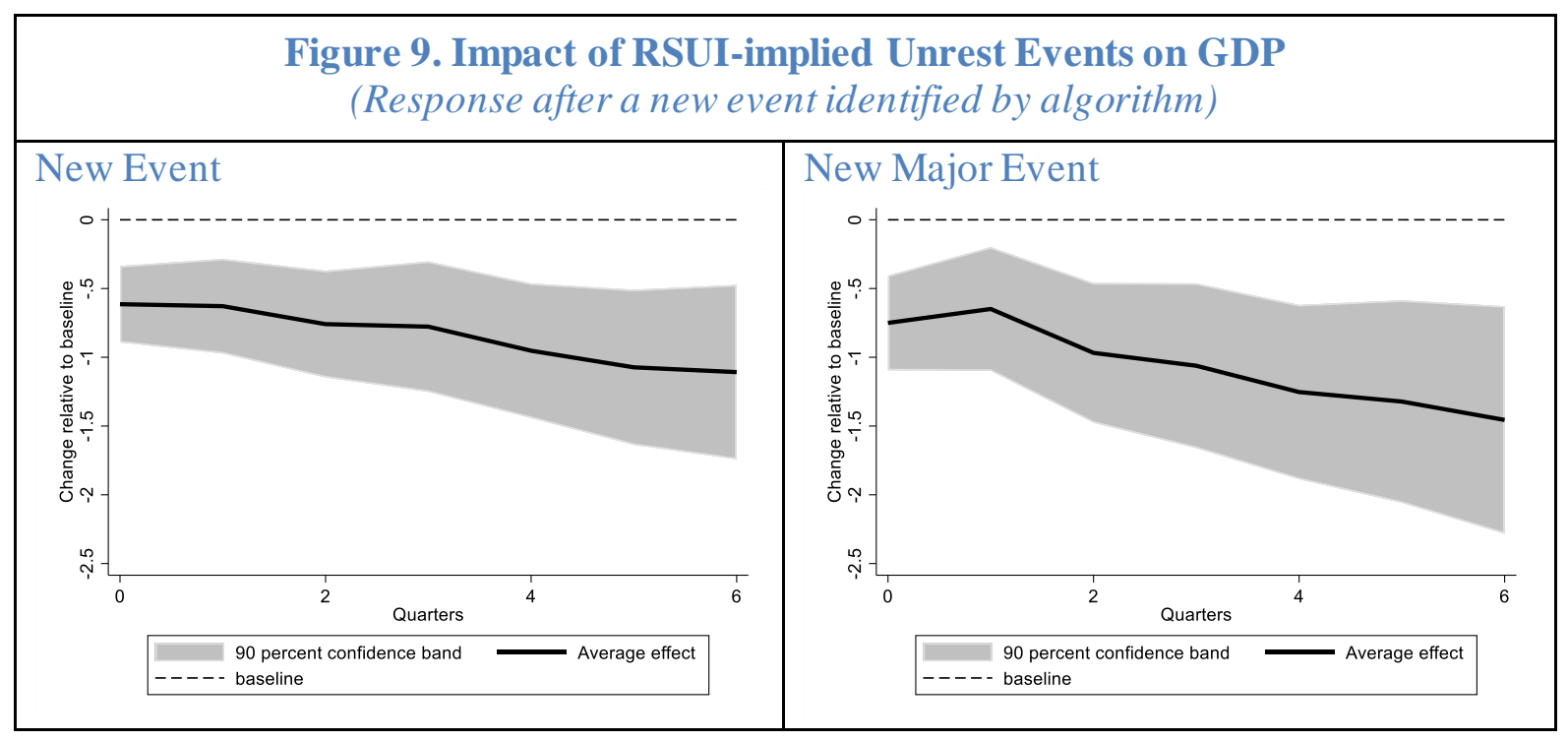

\section{Impact of Different Type of Unrest Events}

Social unrest can be motivated by various socio-economic and/or political reasons and sparked by various triggers. Hence, in Figure 10 we provide a comparison of the impact on economic activity of different types of unrest events (defined by their underlying reasons/triggers, as described in Section III.A). There are several interesting findings. First, all three types of events analyzed - socio-economic, political, and mixed — lead to persistent reductions in economic activity. Second, unrest episodes motivated by socio-economic issues lead to sharper GDP contractions than episodes related to politics/election. Third, episodes triggered by a combination of socio-economic and political factors are associated with largest GDP contractions. Finally, it seems that other events that cannot be labeled as triggered by socio-economic or political factors do not bear a negative effect on economic activity.

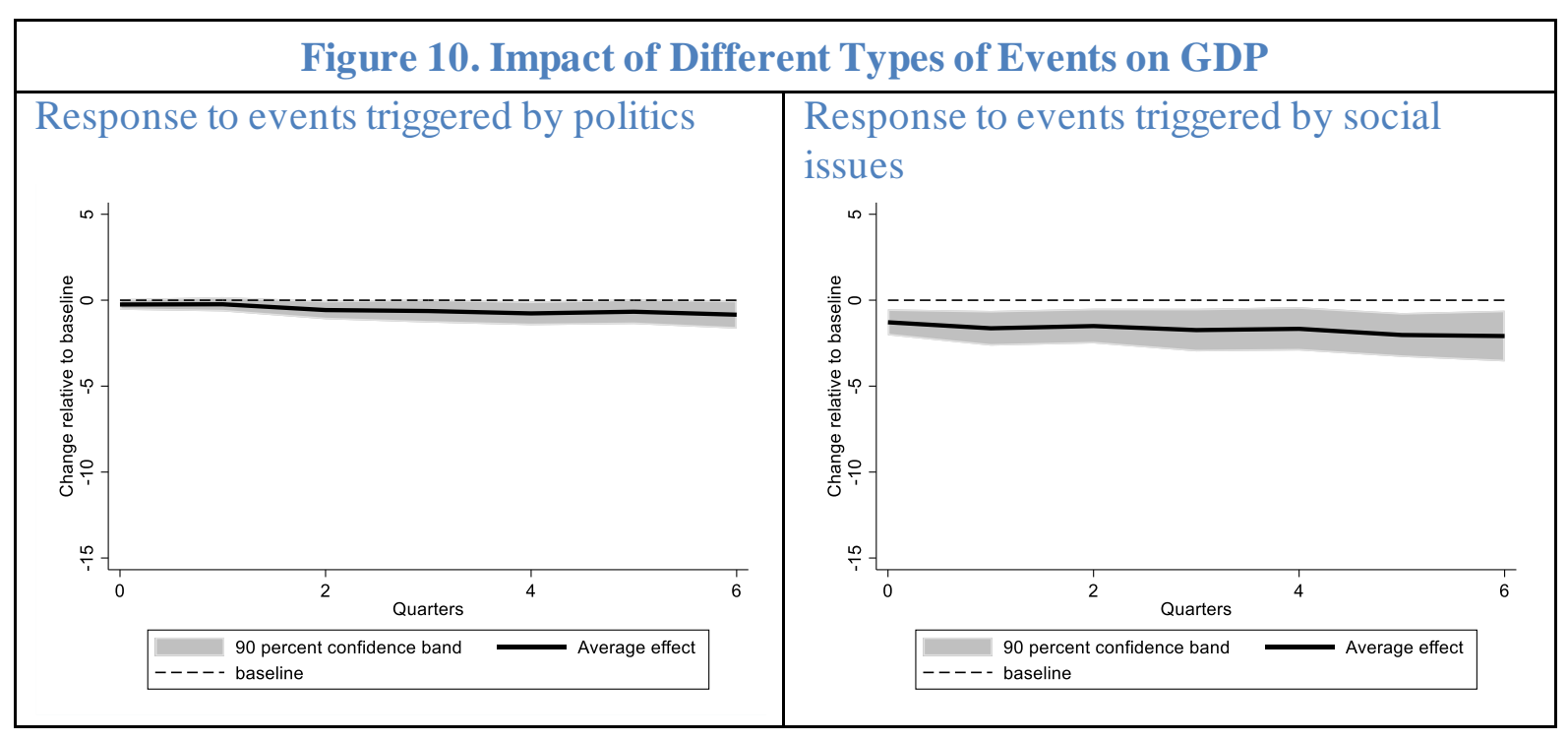




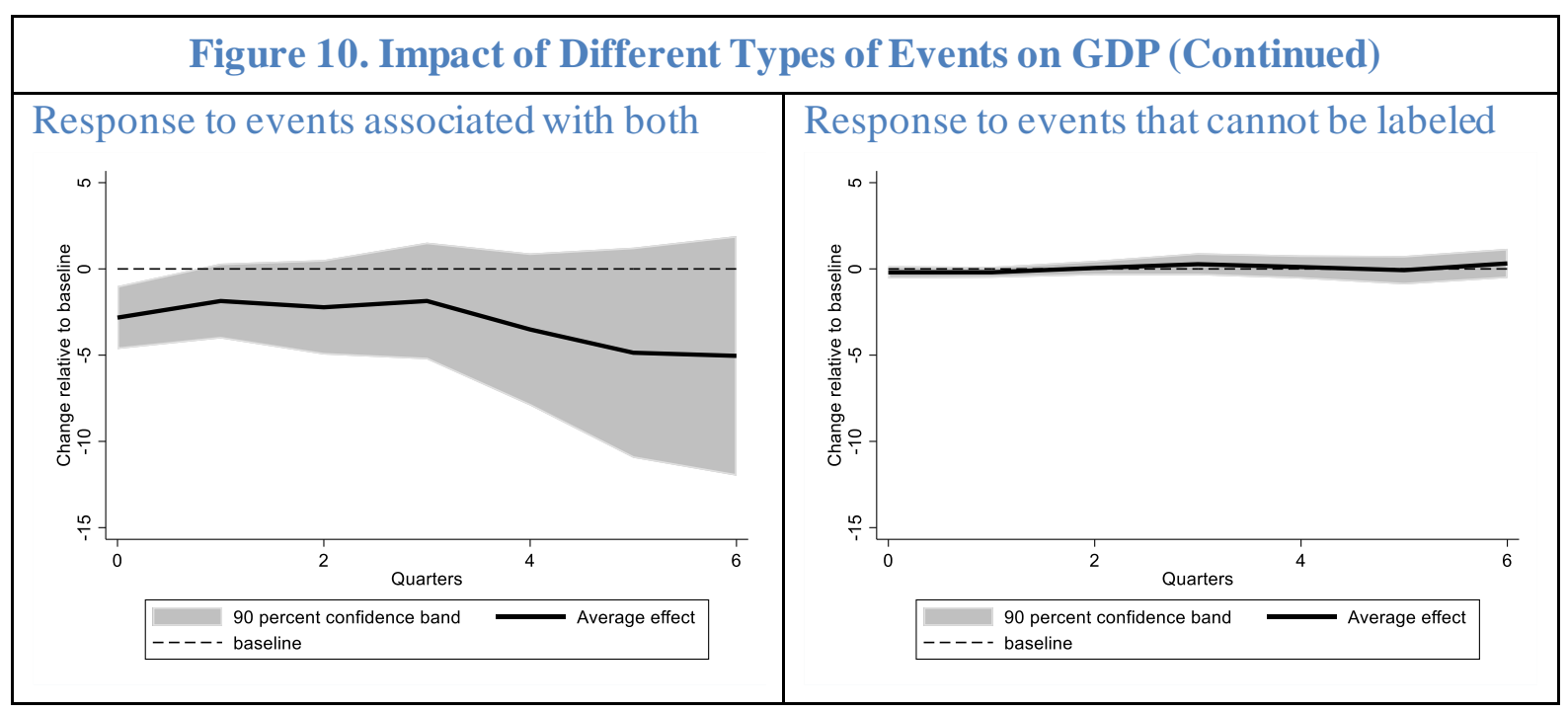

\section{E. Addressing Reverse Causality and Endogeneity Concerns}

The results presented thus far have been interpreted as a causal relationship running from unrest to growth, but this interpretation is subject to caveats. One concern is that unrest may be preceded (maybe caused) by stints of low growth. If this were the case, our results for the effect of social unrest on growth may be picking up the persistence of adverse growth events (reverse causality). Another possibility may be that both unrest and growth are driven by variables that are not properly captured in the econometric specification (omitted variables). For example, fiscal austerity plans can lead to both bouts of social unrest (Ponticelli and Voth, 2020) and economic contractions, in which case the relationship between unrest and growth would be spurious.

While recent work shows that episodes of unrest are hard to predict using observable data, including GDP growth (see Saadi Sedik and, Xu, 2020, and Hlatshwayo and Redl, forthcoming), decreasing the likelihood that our results are driven by reverse causality or omitted variables, this section tackles these concerns in several ways. First, it studies the impact of social unrest in countries that were experiencing low growth prior to the social unrest event and in those that were not. Second, it studies the impact of social unrest on growth in both countries that experience large year-on-year improvements in primary fiscal balances (likely linked to fiscal consolidations) and those that did not. Third, it presents results of an instrumental variables approach that exploits spillovers from recent episodes of unrest in nearby countries.

As a first, exercise, before moving to the econometric analysis of the impact of social unrest on countries with different growth trajectories, Figure 11 shows visually growth patterns before and after episodes of social unrest. It indicates that, on average, there is no clear sign of a decline in growth pre-unrest, apart from possibly three quarters prior to unrest (t-3). This is true when assessing growth and when looking at deviations from the country average. However, Figure 11 (right panel) shows that deviations from average growth are close to or below zero for the four quarters following new episodes of unrest, which is consistent with our estimated negative effect of social unrest on growth. 


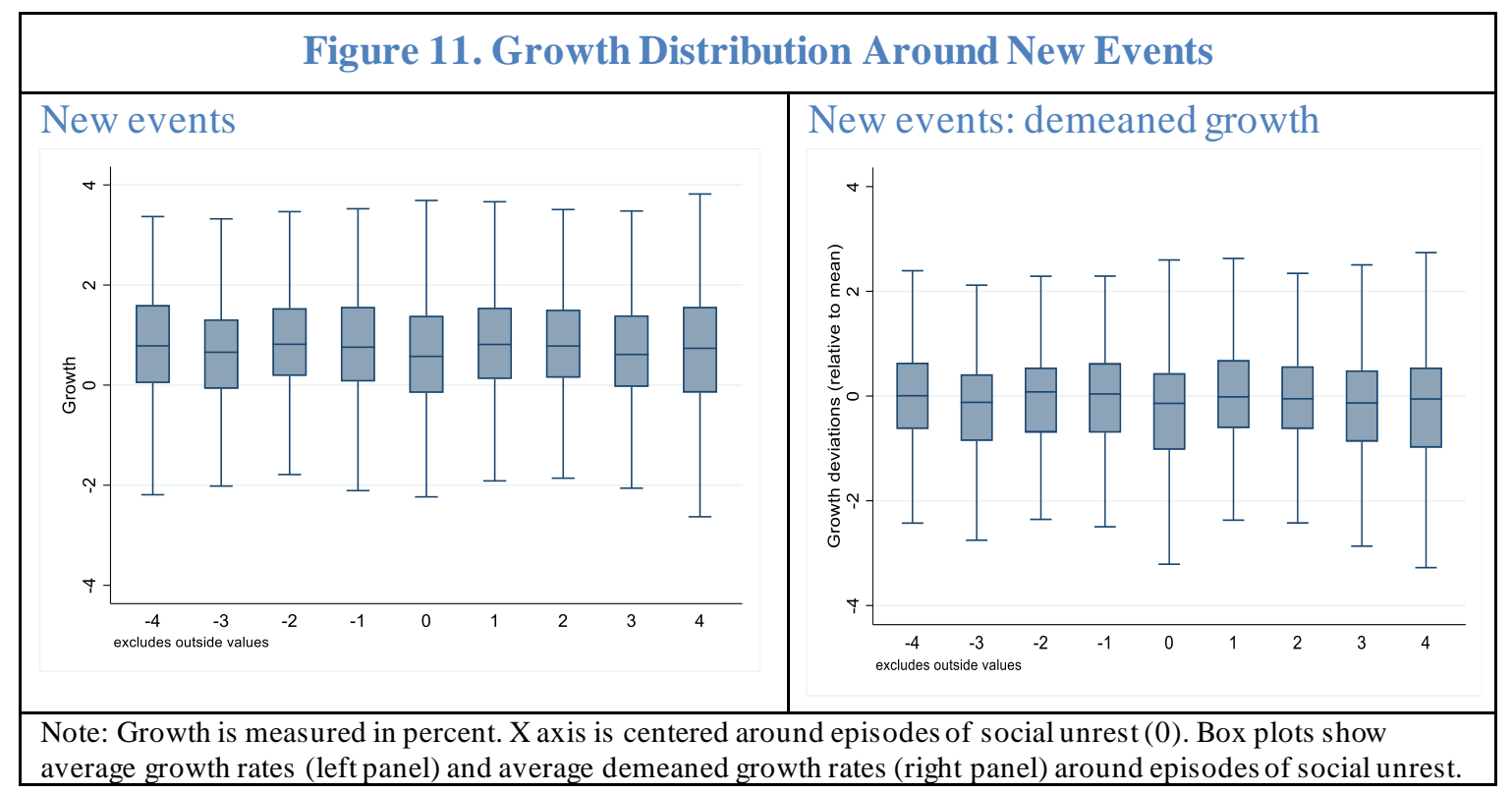

As a second exercise, having shown some indicative descriptive findings, we now turn to a formal regression analy sis controlling for prior adverse growth events, both using the event dummy and the RSUI.

First, we define prior low growth events on the basis of country-specific negative deviations of country growth from the country average growth for at least two out of the last three quarters before the social unrest. Using this definition, 28 percent of the new RSUI-implied events are preceded by low growth events. The results are robust to alternative definitions of a "low growth event" based on: growth deviations from country-specific moving averages, as well as just negative growth in the period before the social unrest. This strategy is implemented both for analysis based in the RSUI and RSUI-derived new events.

More specifically, when using "new event" dummies we run the following regression:

$$
\begin{aligned}
y_{i, t+h}-y_{i, t-1} & =\alpha_{i}^{h}+\gamma_{t}^{h}+\sum_{j=1}^{h} \mu^{j, h} \text { unrest }_{i, t+j}+\beta_{s g}^{h} \text { sg }_{\text {event }_{i, t}}+\beta_{s}^{h} \text { sevent }_{i, t} \\
& +\beta_{g}^{h} \text { gevent }_{i, t}+\theta X_{i, t}+\varepsilon_{i, t+h}
\end{aligned}
$$

Where $\operatorname{sg}_{\text {event }_{i, t}}$ is a dummy taking value one if country $i$ experienced both a social unrest event in period $t$ and two or three quarters of below-average growth in the three quarters preceding the unrest event. The dummy variable $s_{\text {event }}, t$ takes value of one if country $i$ experienced a social unrest event and did not experience two or three quarters of below average growth in the three quarters preceding the identified unrest event. Finally, the dummy variable $g_{\text {event }}$ itt takes value of one if country $i$ experienced two or three quarters of below-average growth prior to period $t$ and did not experience a social unrest event. The excluded group includes countries that neither experienced unrest nor low growth. Such a 
regression allows us to show the results for four mutually exclusive cases: i) only social unrest event; ii) only growth event; iii) both events; and iv) no event.

When using the RSUI, the econometric specification takes the following form:

$$
\begin{aligned}
y_{i, t+h}-y_{i, t-1} & =\alpha_{i}^{h}+\gamma_{t}^{h}+\sum_{j=1}^{h} \mu_{\text {low }}^{j, h} * \operatorname{low}_{i, t} * \text { unrest }_{i, t+j} \\
& +\sum_{j=1}^{h} \mu_{\text {nolow }}^{j, h} *\left(1-\operatorname{low}_{i, t}\right) * \text { unrest }_{i, t+j}+\beta_{\text {low }}^{h} * \operatorname{low}_{i, t} * R S U I \\
& +\beta_{\text {nolow }}^{h} *\left(1-\operatorname{low}_{i, t}\right) * \operatorname{RSUI}_{i, t}+\delta_{\text {low }}^{h} * \operatorname{low}_{i, t} \\
& +\delta_{\text {nolow }}^{h} *\left(1-\operatorname{low}_{i, t}\right)+\left(\operatorname{low}_{i, t} * \theta_{\text {low }} X_{i, t}\right)+\left(\left(1-\operatorname{low}_{i, t}\right) * \theta_{\text {no low }} X_{i, t}\right) \\
& +\varepsilon_{i, t+h}
\end{aligned}
$$

where $l o w_{i, t}$ is a dummy variable that takes value of one if country $i$ experienced two or three quarters of below average growth prior. Thus, $\beta_{\text {low }}^{h}$ captures the effect of an increase in the social unrest index (RSUI) in countries with prior low growth, and $\beta_{\text {no low }}^{h}$ captures the effect of an increase in the social unrest index (RSUI) in countries with no prior low growth.

Figure 12 shows the impact of social unrest on economic activity after controlling for prior adverse growth events, as defined above. Panels 1 and 2 show that adverse growth events are persistent, as expected, but the decline in GDP is larger when growth events are combined with episodes of social unrest. Crucially, Panel 3 shows that social unrest significantly affects growth even if not preceded by adverse growth events, with a GDP contraction of about 1pp after 6 quarters. Similarly, Panel 4 shows that social unrest leads to a larger decline in economic activity in countries experiencing below average growth prior to the unrest event compared to countries that experience below average growth but no social unrest event. The last two results point to the robustness of our results to reverse causality.

Figure 13 shows similar analysis using the RSUI index, focusing on the differential impact of spikes in the social unrest index in countries with low growth prior to the spike and those that did not have low growth prior to the spike. In countries with low prior growth (black line), GDP gradually falls after a one standard deviation increase in the RSUI, and after six quarters it stands approximately -0.2 percentage points below the baseline (countries with low growth and no spike in the index). Countries that did not experience an episode of low growth prior to the spike in RSUI (red line) also suffer a decline in activity. Low growth countries experience a larger contraction on impact, but the medium-term effects are similar for both groups. 
Figure 12. Impact of Social Unrest on GDP After Controlling for Prior Adverse Growth Events

(Response to growth and social unrest events)

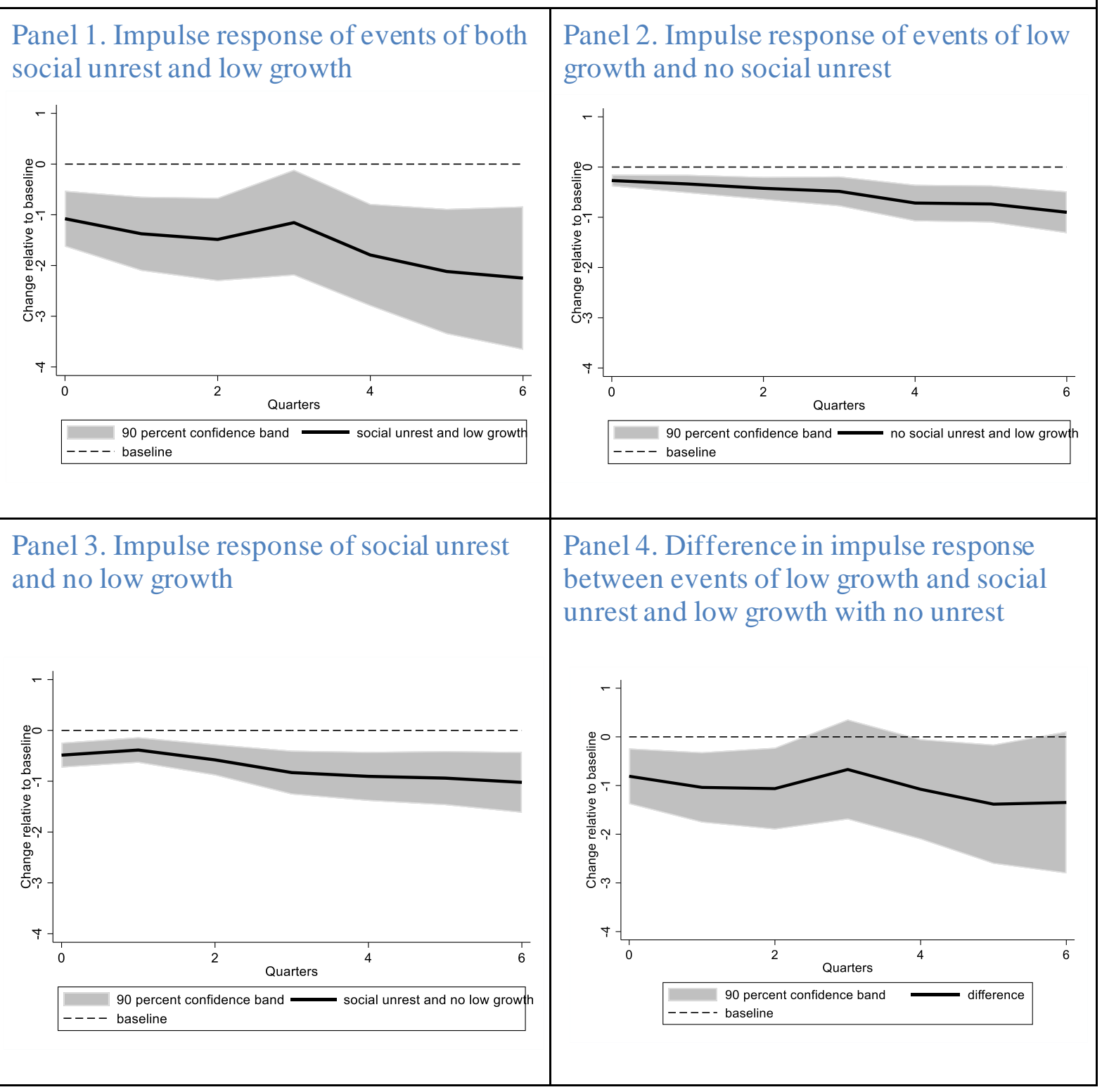


Figure 13. Impact of Social Unrest on GDP After Controlling for Prior Adverse Growth Events

(Response to a one st.dev. shock to the RSUI)

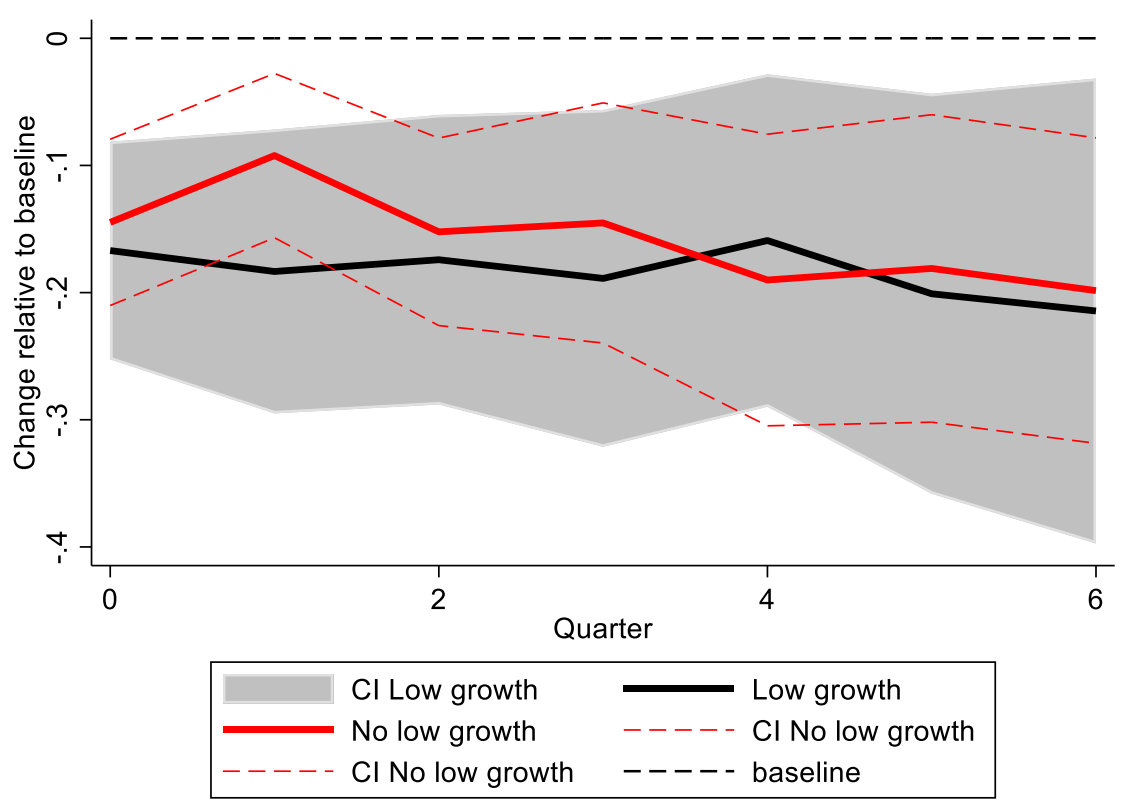

Both the analysis of events and the RSUI confirm that our results are robust to controlling for the possible reverse causality from growth to unrest. Indeed, we find that social unrest has an adverse impact on growth regardless of whether the country was experiencing low growth prior to unrest or not.

As a third exercise, in addition to reverse causality, we focus on the concern that a causal interpretation of our result is blurred by the possibility that the co-movement of GDP and unrest reflects the impact of other factors not captured in our econometric model. To tackle this possibility, we follow two approaches. First, we explicitly control for a potential driver of both unrest and activity: fiscal consolidations. Indeed, there is broad consensus that fiscal consolidations have an adverse effect on economic activity (although the effect would depend on the composition of the consolidation as discussed in Alesina, Favaro, and Giavazzi, 2019), but at the same time episodes of fiscal consolidation are often linked with protests and socio-political instability (Ponticelli and Voth, 2020). Second, we exploit waves of unrest in nearby countries to instrument social unrest.

To study whether our results are picking-up the link between fiscal austerity and economic activity and unrest, respectively, we estimate an econometric specification that distinguishes between the effect of social unrest in countries that experience episodes of fiscal austerity and those that do not. In particular, we estimate the following specification: 


$$
\begin{aligned}
y_{i, t+h}-y_{i, t-1} & =\alpha_{i}^{h}+\gamma_{t}^{h}+\sum_{j=1}^{h} \mu_{\text {cons }}^{j, h} * \text { cons }_{i, t} * \text { unrest }_{i, t+j} \\
& +\sum_{j=1}^{h} \mu_{\text {nocons }}^{j, h} *\left(1-\text { cons }_{i, t}\right) * \text { unrest }_{i, t+j}+\beta_{\text {cons }}^{h} * \text { cons }_{i, t} * \text { unrest }_{i, t} \\
& +\beta_{\text {no cons }}^{h} *\left(1-\text { cons }_{i, t}\right) * \text { unrest }_{i, t}+\delta_{\text {cons }}^{h} * \text { cons }_{i, t} \\
& +\delta_{\text {no cons }}^{h} *\left(1-\text { cons }_{i, t}\right)+\theta_{\text {cons }} * \text { cons }_{i, t} * X_{i, t}+\theta_{\text {no cons }} *\left(1-\text { cons }_{i, t}\right) \\
& * X_{i, t}+\varepsilon_{i, t+h}
\end{aligned}
$$

Where cons $_{i, t}$ is a dummy variable taking value one if country $i$ 's primary fiscal deficit over GDP increased by more than 2 percentage points from one year to the other, and unrest $_{i, t}$ captures either RSUI or the RSUI-implied dummy.

The results in Figure 14 show that social unrest has an adverse effect on economic activity, regardless of whether a country is immersed in a fiscal consolidation effort. Hence, the adverse impact of social unrest on economic activity estimated in countries that are not experiencing episodes of fiscal austerity suggests that social unrest affects GDP beyond the potential role played by fiscal consolidations.

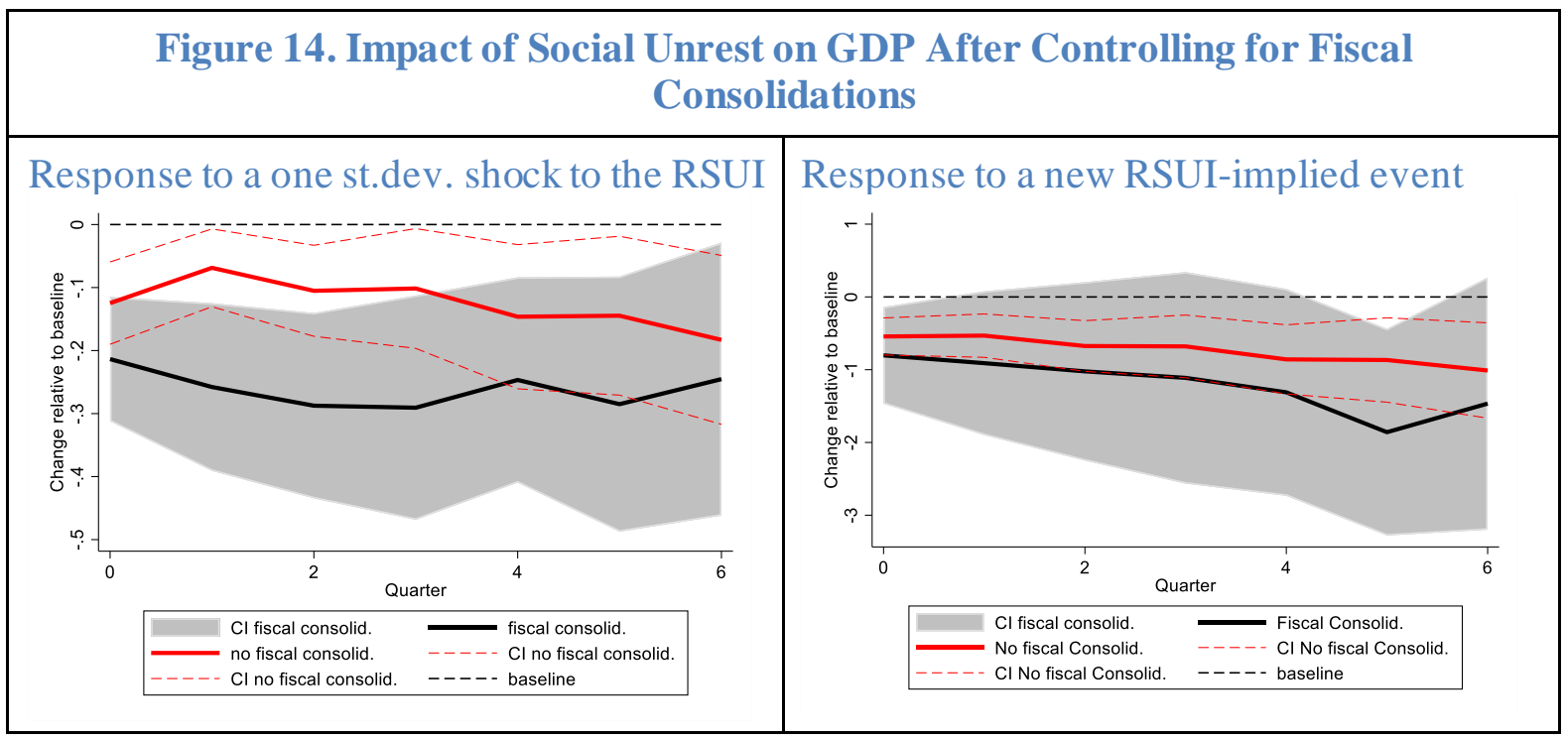

We turn to presenting results for a panel regression instrumental variables (IV) strategy where we exploit the timing of unrest episodes across countries. More specifically, we instrument social unrest in country $i$ with current and past episodes of social unrest in nearby countries. As documented in Barrett et al. (2020), episodes of social unrest generate spillovers at the regional level: social unrest in one country is associated with a 1 percent increase in the probability that neighbors experience social unrest in the next six months. This identification strategy (namely, identification through regional waves) has been also used to study the causal effects of democratization on growth (Acemoglu et al. 2019) and to study the impact of fiscal austerity on social unrest (Ponticelli and Voth, 2020). For robustness, when operationalizing the instrument, we construct three versions of the variable 
capturing "regional waves". The first is a distance-weighted measure of social unrest for country $i$ 's partners, as follows:

$$
\text { unrest }_{i, t}^{-i, w}=\sum_{j \in W_{-i}} \frac{1 / \log \left(\text { dist }_{i j}\right)}{\sum_{k \in W_{-i}} 1 / \log \left(\text { dist }_{i k}\right)} \text { unrest }_{j, t}
$$

Where $W_{-i}$ is the set of all countries with available data on social unrest excluding country $i$, unrest $_{j, t}$ is either RSUI or the RSUI-implied events, and $d_{i s t}{ }_{i j}$ is the bilateral populationweighted distance between country $i$ and country $j$, as presented in the CEPII Geodist dataset. The second measure is a similar index using only regional partners (where regions are defined using the IMF regional classification), unrest $_{i, t}^{-i, R}$, and the third one is an index that only takes into account contiguous countries (countries sharing a land border), regardless of their region, unrest ${ }_{i, t}^{-i, C}$. With those indices, we follow an IV strategy where RSUI and the RSUI-implied events are instrumented using, in turn, unrest $_{i, t}^{-i, w}$ and its lagged values, unrest $_{i, t}^{-i, R}$ and its lagged values, and unrest $_{i, t}^{-i, C}$ and its lagged values ${ }^{4}$. In the first stage we also include region-time fixed effects to capture any regional time-varying variable that may affect waves of unrest.

The results confirm the finding that both spikes in the RSUI and episodes of social unrest lead to lower GDP compared to countries that do not suffer social unrest. A one standard deviation increase in RSUI leads to a 0.2 to 0.3 decline in GDP on impact, depending on the instrument used (Figure 15).5 As in the baseline specification, the impact of social unrest in the IV specification are also persistent over our 6 -quarter window. As is usually the case, IV estimates are larger in magnitude compared to the standard panel regressions.

\footnotetext{
${ }^{4}$ In each case we instrument the unrest variable with both $R S U I_{i, t}^{-i}$ and two la gs and $e v e n t_{i, t}^{-i}$ and two la gs.

${ }^{5}$ The annex shows results u sing a GDP-weighted index of unrest, with similar quantitativeimpacts.
} 
Figure 15. Impact of Social Unrest on GDP, Instrumental Variables Approach (Response to a one st.dev. shock to the RSUI)

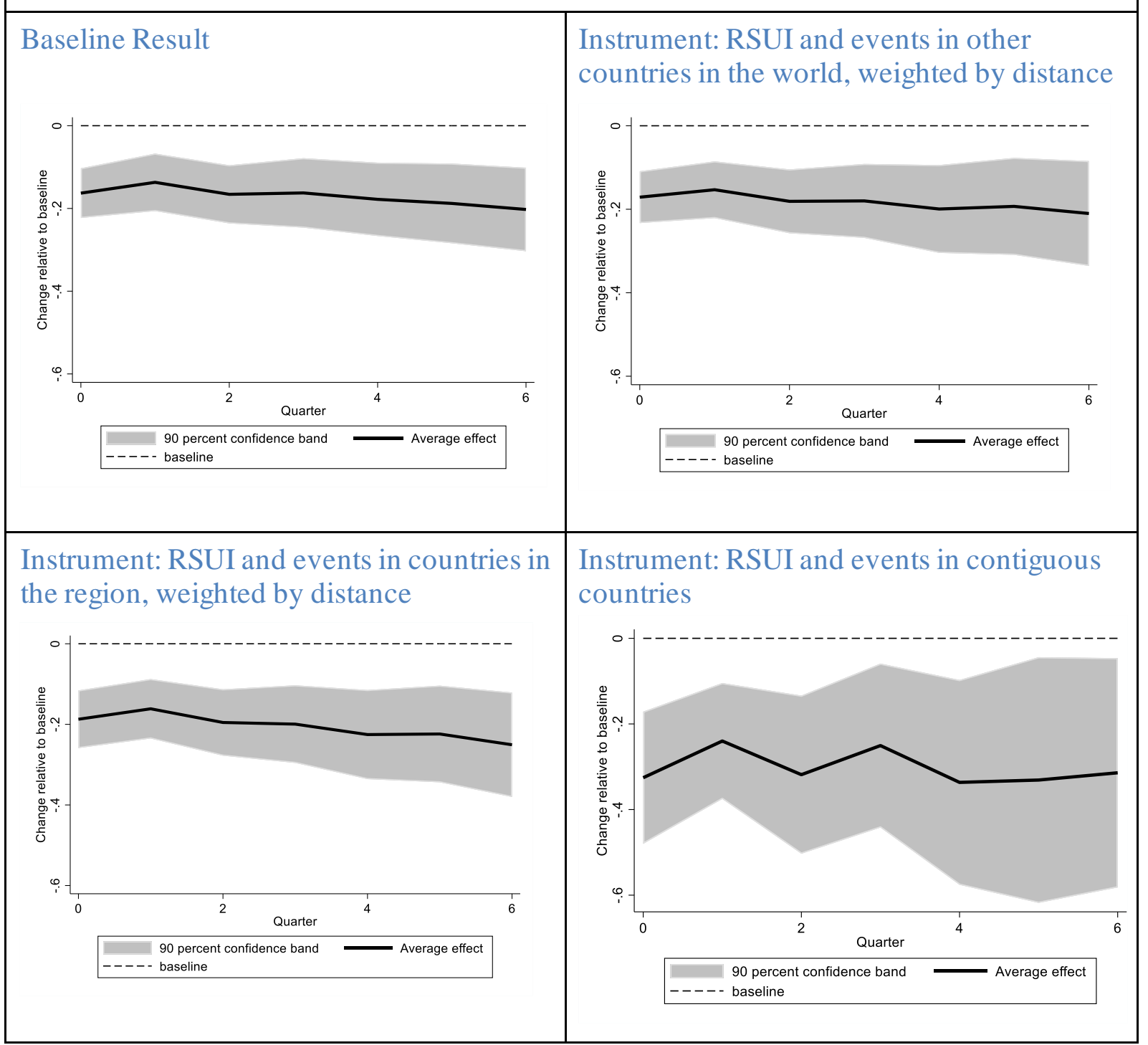

Similar results are obtained when studying the impact of RSUI-implied unrest events. New episodes of social unrest lead to a 1 to 2 percent decline in GDP on impact relative to baseline, and the impact grows to 2 to 3 percentage points after 6 quarters. The estimated effects are roughly 2 to three times as large as those in the baseline specification. 
Figure 16. Impact of Social Unrest on GDP, Instrumental Variables Approach (Response to a new RSUI-Implied event)

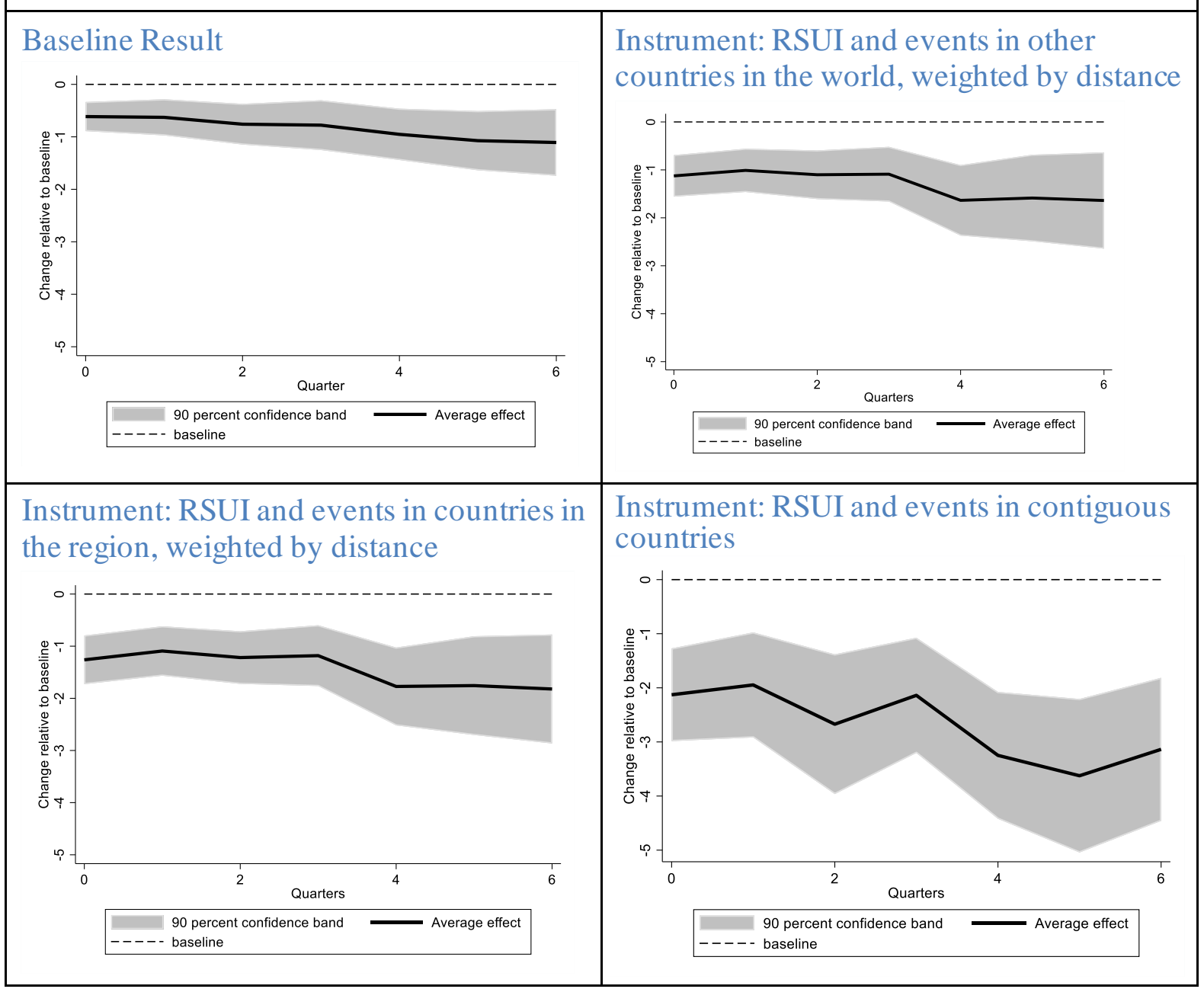

\section{Conclusions}

Using a novel, timely and transparent indicator for social unrest based on media word count metrics, this study investigates the macroeconomic effects of social unrest. The analysis provides several contributions to the existing literature - it includes a broader pool of social unrest events and investigates the impact on a set of higher-frequency economic indicators.

The analysis draws several key conclusions. First, economic activity declines following a one standard deviation increase in the social unrest index, with GDP remaining on average 0.2 percentage points below the pre-shock level after 6 quarters. Second, the adverse effect on GDP is driven by sharp contractions of services and manufacturing (from sectoral perspective) and consumption (from demand side). Third, social unrest is found to dampen (consumer) confidence and raise uncertainty. While unrest is found to adversely affect country groups regardless of their income level, the effect upon emerging markets seems to be (about two times) larger than in advanced economies. Fourth, strong institutions and available policy space can dampen the adverse effects of unrest. Fifth, the effects are larger when considering major events of social unrest - which are increases of at least 4 standard 
deviations in the RSUI — as, on average, GDP remains 1 percentage points below baseline after 6 quarters of such a social unrest event. Hence, the effect of such major effects is more than proportional than implied by the results for RSUI above, but consistent with the notion that major shocks have relatively larger impact. For comparison, the impact of social unrest events is larger than the impact on oil exporters' GDP of an oil price plunge and is comparable to the impact of an oil price plunge combined with a recession (World Bank, 2020). The impact of unrest on GDP is consistent and quantitatively similar to the findings Barrett et al. (2021), who study the behavior of stock market returns after episodes of social unrest. Sixth, unrest episodes motivated by socio-economic considerations result in sharper GDP contractions compared to those associated mainly with politics/elections; and episodes triggered by a combination of both socio-economic and political issues see the sharpest contractions. Finally, the results are robust to controlling for previous adverse growth events, thereby addressing some of the possible reverse causality concerns, to controlling for episodes of fiscal consolidation, and to the implementation of an instrumental variables strategy that exploits regional waves of social unrest. 


\section{REFERENCES}

Acemoglu, D. and J. Robinson (2019). The Narrow Corridor: States, Societies, and the Fate of Liberty. New York: Penguin Press.

Acemoglu, D., S. Naidu, P. Restrepo, and J. A. Robinson (2019). "Democracy does cause growth," Journal of Political Economy 127 (1), 47-100.

Alesina, A., C. Favero and F. Giavazzi (2019). "Effects of Austerity: Expenditure- and Tax-Based Approaches," Journal of Economic Perspectives, vol. 33(2), pages 141-162

Ahir, H., N. Bloom, and D. Furceri (2018), “The World Uncertainty Index”.

Aisen, A. and F.J. Veiga (2013), "How does political instability affect economic growth?", European Journal of Political Economy, 29, 151-167.

Alesina, A. and R. Perotti (1996), "Income distribution, political instability, and investment," European Economic Review, 40, 1203-1228.

Auerbach, A. and Y. Gorodnichenko (2012), "Measuring the Output Responses to Fiscal Policy,” American Economic Journal: Economic Policy, 4(2): 1-27.

Barrett, Ph., M. Appendino, K. Nguyen, J. de Leon Miranda (2020), "Measuring Social Unrest Using Media Reports”, IMF Working Paper 20/129. Washington, DC.

Barrett, Ph., M. Bondar, S. Chen, M. Chivakul, D. Igan (2021), “Pricing Protest: The Response of Financial Markets to Social Unrest", IMF Working Paper 2021/079. Washington, DC., Washington, DC.

Barrett, Ph., and S. Chen, (2021), "Social Repercussions of Pandemics", IMF Working Paper 2021/021, Washington, DC.

Cerra, V. and S. Saxena (2008), "Grow th Dynamics: The Myth of Economic Recovery", American Economic Review 98:1, 439-457.

Furceri, D, P Loungani, J D Ostry, and P Pizzuto, 2020, "Will Covid-19 affect inequality? Evidence from past pandemics," Covid Economics 12: 138-57.

Gruss, B. and S. Kebhaj, 2019. "Commodity Terms of Trade: A New Database", IMF Working Paper 19/21.

Hlatshwayo and Redl (forthcoming), "The Macroeconomic Relevance of Social Unrest”, IMF Working Paper (forthcoming), Washington, DC.

Hlatshwayo and Redl (forthcoming), "Forecasting Social Unrest", IMF Working Paper (forthcoming), Washington, DC. 
Ilzetzki, E., C. M. Reinhart, and K. S. Rogoff (2019), "Exchange Arrangements Entering the 21 st Century: Which Anchor Will Hold?” Quarterly Journal of Economics 134 (2): 599-646.

IMF (2019), "The Economic Consequences of Conflicts", Chapter 2 in Sub-Saha ran Africa Regional Economic Outlook: Recovery Amid Elevated Uncertainty, International Monetary Fund, Washington, DC.

IMF (2020), World Economic Outlook, October 2020, Washington, DC.

Institute for Economics and Peace (2020), Global Peace Index 2020: Measuring Peace in a Complex World, Sydney.

Jong-A-Pin, R. (2009), “On the measurement of political instability and its impact on economic growth”, European Journal of Political Economy, 25, 15-29.

Jordà, O. (2005), "Estimation and inference of impulse responses by local projections," American Economic Review 95: 161-182.

Kaufmann, D., A. Kraay, M. Mastruzzi (2010), “The Worldwide Governance Indicators: Methodology and Analytical Issues”, Policy Research Working Paper WPS 5430.

World Bank. Washington, DC.

Novta, N. and E. Pugacheva (2020), “The Macroeconomic Costs of Conflict”, IMF Working Paper 20/110, International Monetary Fund, Washington, DC.

Ponticelli, J. and H.-J. Voth (2020). "Austerity and anarchy: Budget cuts and social unrest in europe, 1919-2008,” Journal of Comparative Economics 48 (1), 1-19

Ramey, V. A., and S. Zubairy (2018), "Government Spending Multipliers in Good Times and in Bad: Evidence from US Historical Data," Journal of Political Economy, University of Chicago Press, vol. 126(2), pages 850-901.

Rodrik, D. (1999), "Where Did All the Growth Go? External Shocks, Social Conflict, and Growth Collapses", Journal of Economic Growth, 4, 385-412.

Rother, B., G. Pierre, D. Lombardo, R. Herrala, P. Toffano, E. Roos, G. Auclair, and K. Manasseh (2016), "The Economic Impact of Conflicts and the Refugee Crisis in the Middle East and North Africa", IMF Staff Discussion Note 16/08, International Monetary Fund, Washington, DC.

Saadi Sedik, T. and R. Xu (2020), "A Vicious Cycle: How Pandemics Lead to Economic Despair and Social Unrest”, IMF Working Paper 20/216, Washington, DC.

Teulings, C.N. and N. Zubanov (2014), "Is Economic Recovery a Myth? Robust Estimation of Impulse Responses", Journal of Applied Econometrics 29, p. 497-514.

World Bank (2020), Global Economics Prospects, June 2020. Washington, DC: World Bank. 


\section{ANNEXES}

\section{A. The Role of Structural Factors}

This Annex investigates whether structural factors may mitigate/amplify the impact of social unrest. Figure A1 explores how product market competition and labor market flexibility affect the response of economic activity following episodes of social unrest. Given the structural nature of these characteristics, our prior was that they would affect the medium-term performance, but not necessarily the immediate response to social unrest (within our horizon of interest of up to 6 quarters). The findings in Figure A1 show that low product market competition seems to amplify the negative impact of social unrest on economic activity, while labor market flexibility does not seem to make a significant difference on the negative effect of unrest on growth. Such difference is somewhat puzzling and warrants a deeper analysis, which goes beyond the scope of this paper.

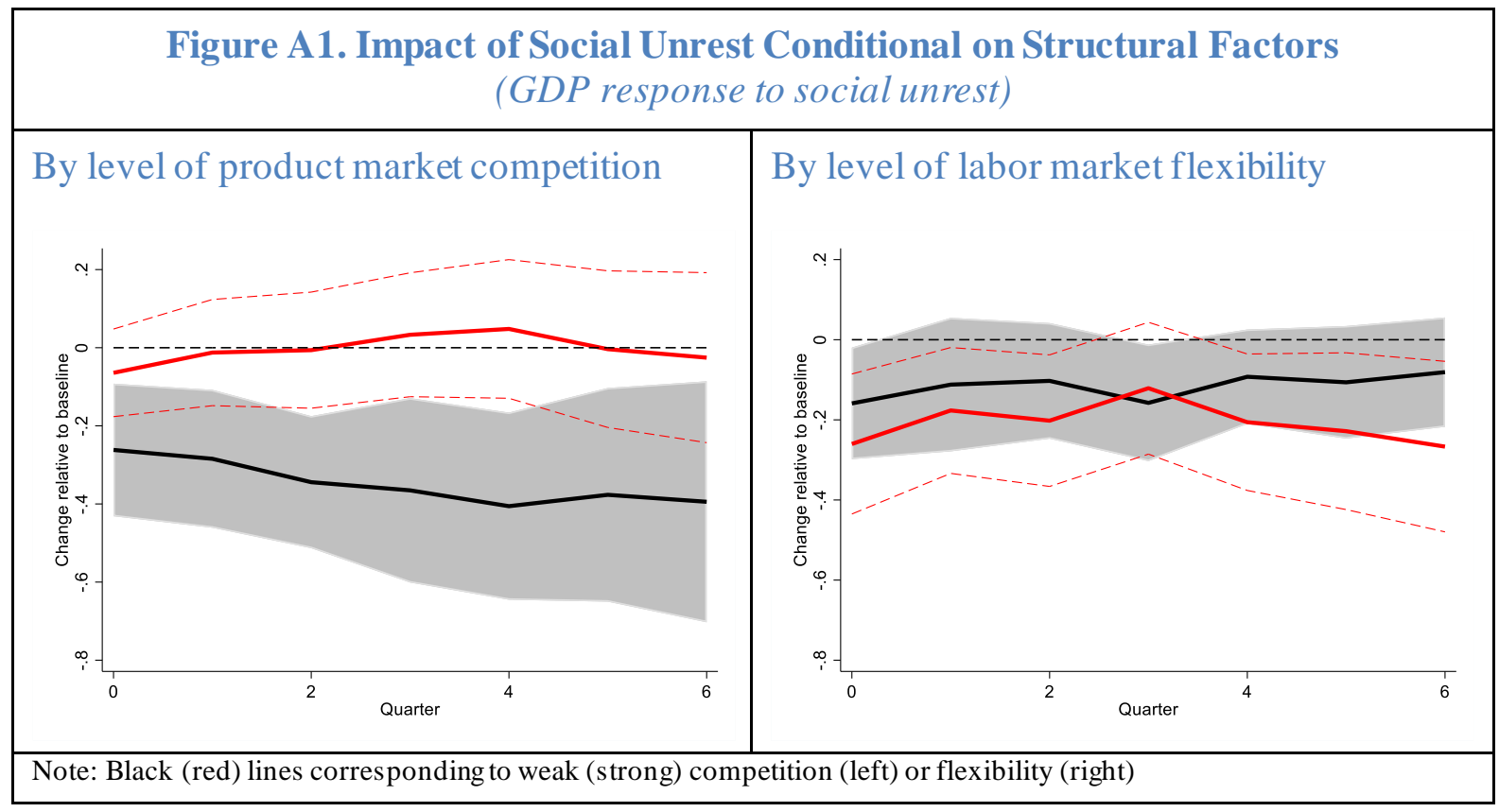




\section{B. Instrumental Variables Strategy Using GDP Weights}

This Annex presents results for an IV approach that instruments social unrest with a GDP-weighted index of global and regional unrest. In particular, for each country $i$, we construct a variable capturing global and regional unrest at time $t$ following equation (6), but we weight unrest in country $j$ by $\frac{\log \left(G D P_{j}\right)}{\sum_{k \in K_{-i}} \log \left(G D P_{k}\right)}$, where $K_{-i}$ is either the set of countries other than $i$ in our full sample or in $i$ 's region.

Figure B1 shows that a one standard deviation increase in the RSUI leads to a persistent decline in GDP of approximately -0.2 percentage points relative to baseline over a 6 -quarter window. The results are quantitatively similar to those presented in Figure 15. Similarly, Figure B2 shows that GDP experiences a persistent decline of 1 percentage points relative to baseline after an RSUI-implied event of social unrest.

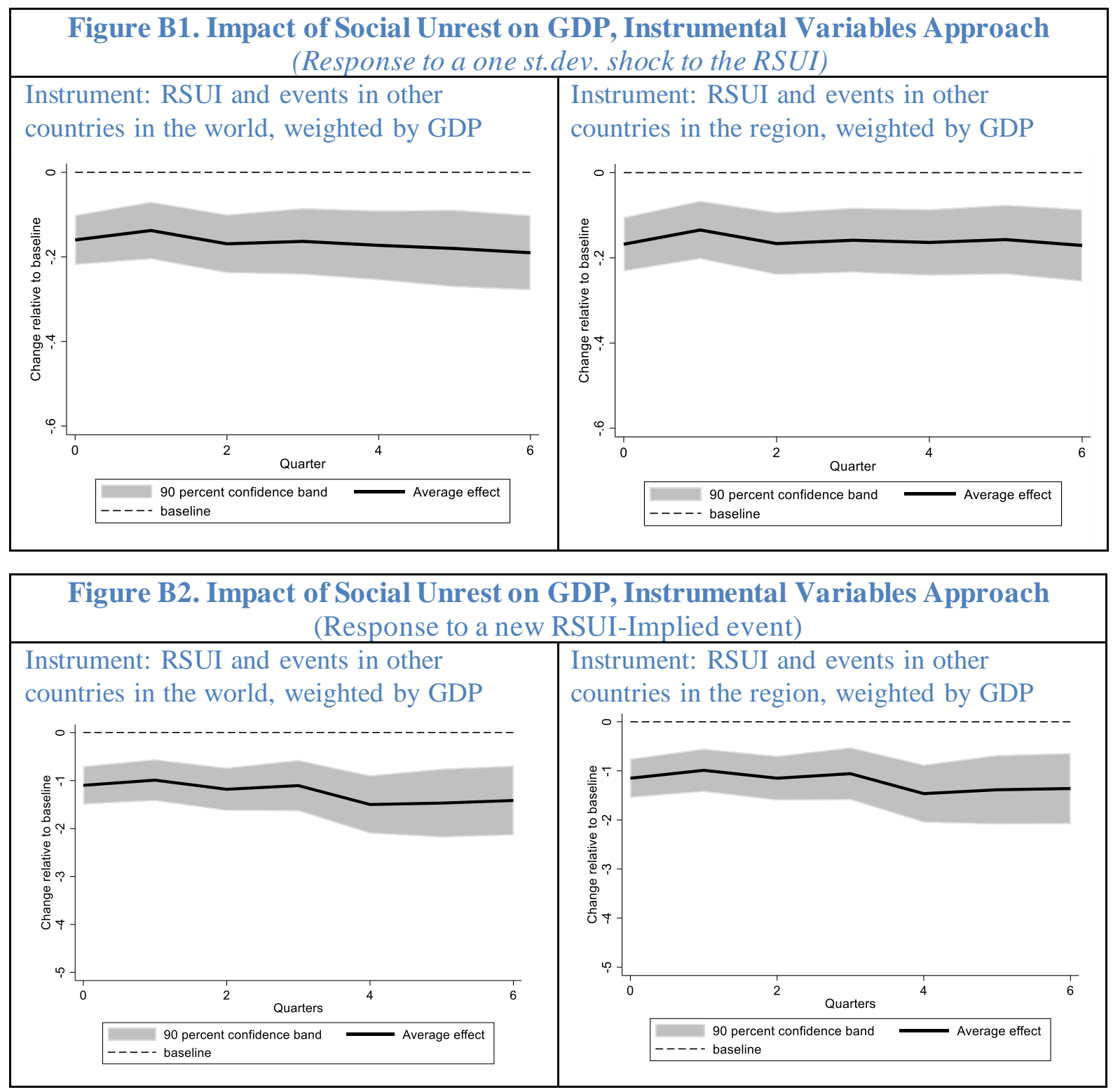

